\title{
Analysis of apparent optical properties and ocean color models using measurements of seawater constituents in New England continental shelf surface waters
}

\author{
Rebecca E. Green and Heidi M. Sosik \\ Biology Department, Woods Hole Oceanographic Institution, Woods Hole, Massachusetts, USA \\ Received 22 May 2003; revised 10 December 2003; accepted 14 January 2004; published 17 March 2004.
}

[1] We used budgets of absorption $(a)$, scattering $(b)$, and backscattering $\left(b_{b}\right)$ for particles and chromophoric dissolved organic matter (CDOM) to investigate sources of seasonal variations in apparent optical properties (AOPs) of New England continental shelf surface waters. Spectral $a, b$, and $b_{b}$ budgets for particles were estimated from flow cytometric measurements of eukaryotic pico/nanophytoplankton, Synechococcus, heterotrophic prokaryotes, detritus, and minerals; AOPs were modeled with Hydrolight radiative transfer software. For late summer and spring, our modeled values of the diffuse attenuation coefficient $\left(K_{d}\right)$ and remote sensing reflectance $\left(R_{\mathrm{rs}}\right)$ were on average within $15 \%$ and $9 \%$, respectively, of independent measurements. This close agreement allowed us to examine how different seawater constituents contributed to AOP variability. Higher values of $K_{d}$ in the spring, compared to summer, were due to higher absorption by eukaryotic phytoplankton $\left(a_{\text {euk }}\right)$ and CDOM $\left(a_{\mathrm{CDOM}}\right)$, which coincided with higher nutrient levels and less stratified conditions than in the summer. Differences in the spectral shape of $R_{\mathrm{rs}}$ between the seasons were caused by a combination of differences in $a_{\text {euk }}, a_{\mathrm{CDOM}}$, and $b_{b}$ from non-phytoplankton particles (minerals and detritus combined). For nonphytoplankton $b_{b}$ the major seasonal difference was a higher inverse wavelength dependence in the summer due to the effects of small organic detritus. We applied two semianalytical ocean color models to our data, in order to evaluate whether the assumptions and parameterizations inherent in these models are applicable for New England shelf waters. We show how differences between observed and modeled chlorophyll $a$ specific phytoplankton absorption, $a_{\mathrm{CDOM}}$, and non-phytoplankton $b_{b}$ cause errors in chlorophyll $a$ concentration and IOPs retrieved from reflectance inversion models. INDEX TERMS: 4847 Oceanography: Biological and Chemical: Optics; 4219 Oceanography: General: Continental shelf processes; 4275 Oceanography: General: Remote sensing and electromagnetic processes (0689); 4227 Oceanography: General: Diurnal, seasonal, and annual cycles; KEYWORDS: optical properties, suspended particulate matter, ocean color

Citation: Green, R. E., and H. M. Sosik (2004), Analysis of apparent optical properties and ocean color models using measurements of seawater constituents in New England continental shelf surface waters, J. Geophys. Res., 109, C03026, doi:10.1029/2003JC001977.

\section{Introduction}

[2] Semianalytical ocean color algorithms are based on the parameterization of apparent optical properties (AOPs), such as diffuse attenuation coefficients for downwelling irradiance $\left(K_{d}\right)$ and remote sensing reflectance $\left(R_{\mathrm{rs}}\right)$, as functions of inherent optical properties (IOPs) and other factors such as chlorophyll $a$ concentration ([Chl]) (see Table 1 for symbols used in this paper). To first order, $K_{d}$ is related to the absorption coefficient $\left(K_{d} \propto a\right)$, and $R_{\mathrm{rs}}$ is proportional to the ratio of backscattering to absorption coefficients $\left(R_{\mathrm{rs}} \propto b_{b} / a\right)$ [Gordon et al., 1975; Morel and Prieur, 1977]. Two uncertainties related to describing ab-

Copyright 2004 by the American Geophysical Union. 0148-0227/04/2003JC001977\$09.00 sorption in bio-optical algorithms include the effects of phytoplankton community structure [Sathyendranath et al., 2001] and variability in the ratio between algal absorption and nonalgal absorption [Garver and Siegel, 1997; Morel and Maritorena, 2001; Sathyendranath et al., 2001]. An important difficulty arises because there is not a reliable relationship between nonalgal absorption and [Chl]. Furthermore, relationships between [Chl] and scattering $(b)$ have significantly more unexplained variance than do relationships between [Chl] and $a$ [Gordon and Morel, 1983], and no reliable relationship exists between particle $b_{b}$ and [Chl]. Perhaps the most uncertainty in current bio-optical models is associated with the modeling of $b_{b}$ by particles, since the main contributors are thought to be small nonalgal particles of less than $1 \mu \mathrm{m}$ in size for which few measurements have been made [Stramski and Kiefer, 1991; Green et 
Table 1. Definitions of Symbols

\begin{tabular}{|c|c|}
\hline Symbol & Description \\
\hline IOP & inherent optical property \\
\hline AOP & apparent optical property \\
\hline FCM & flow cytometric \\
\hline [Chl] & chlorophyll $a$ concentration, $\mathrm{mg} \mathrm{m}^{-3}$ \\
\hline CDOM & chromophoric dissolved organic matter \\
\hline$n$ & $\begin{array}{l}\text { real refractive index, relative to seawater } \\
(n=1.339 \text { relative to a vacuum })\end{array}$ \\
\hline$n^{\prime}$ & $\begin{array}{l}\text { imaginary refractive index, } \\
\text { relative to } n \text { of seawater }\end{array}$ \\
\hline$a$ & absorption coefficient, $\mathrm{m}^{-1}$ \\
\hline$b$ & scattering coefficient, $\mathrm{m}^{-1}$ \\
\hline$b_{b}$ & backscattering coefficient, $\mathrm{m}^{-1}$ \\
\hline$a_{x}, b_{x}, c_{x}, b_{b, x}$ & $\begin{array}{l}\text { optical coefficients where } \mathrm{x} \text { is a particular seawater } \\
\text { constituent, for example, } a_{p} \text { is particulate absorption } \\
\text { and } b_{b, \text { det }} \text { is detrital backscattering, } \mathrm{m}^{-1}\end{array}$ \\
\hline$\sigma_{a}, \sigma_{b}, \sigma_{b b}$ & optical cross-sections, $\mathrm{m}^{2}$ \\
\hline$\tilde{b}_{b}$ & backscattering ratio, $b_{b} / b$ \\
\hline$S$ & spectral slope for $a_{\mathrm{cdm}}, \mathrm{nm}^{-1}$ \\
\hline Y & spectral power law exponent for $b_{b, p}$ \\
\hline$R_{\mathrm{rs}}$ & remote sensing reflectance, $\mathrm{sr}^{-1}$ \\
\hline$R$ & irradiance reflectance \\
\hline$K_{d}$ & downwelling diffuse attenuation, $\mathrm{m}^{-1}$ \\
\hline$a_{\mathrm{ph}}^{*}$ & $\begin{array}{l}\text { chlorophyll } a \text { specific absorption } \\
\text { coefficient, } \mathrm{m}^{2}(\mathrm{mg} \mathrm{chl} a)^{-1}\end{array}$ \\
\hline$L_{u}$ & upwelling radiance, $\mathrm{W} \mathrm{m} \mathrm{m}^{-2} \mathrm{~nm}^{-1} \mathrm{sr}^{-1}$ \\
\hline$E_{d}$ & downwelling irradiance, $\mathrm{W} \mathrm{m}^{-2} \mathrm{~nm}^{-1}$ \\
\hline$E_{u}$ & upwelling irradiance, $\mathrm{W} \mathrm{m}^{-2} \mathrm{~nm}^{-1}$ \\
\hline
\end{tabular}

al., 2003b]. In a recent review, Morel and Maritorena [2001] concluded that purely analytical approaches to ocean color algorithms, ideally based on radiative transfer calculations, remain problematic because of the insufficient knowledge of the phase function and backscattering efficiency of oceanic particles.

[3] A major source of particulate $b_{b}$ in the oceans is thought to be small $(<1 \mu \mathrm{m})$, numerically abundant detrital and/or mineral particles. Little is known about this fraction of particles, but Stramski and Kiefer [1991] conjectured on the basis of calculations with Mie theory that two groups of particles may be important backscatterers: (1) fine particles of diameter near $0.3 \mu \mathrm{m}$ and $(2)$ high refractive index $(n \approx$ 1.15-1.20) particles ranging between 2 and $10 \mu \mathrm{m}$ in diameter. A type of particles that fits the first group was measured by Koike et al. [1990] using epifluorescence microscopy and particle counting; they were described as small $(<0.6 \mu \mathrm{m})$, nonliving particles with high water and organic matter content. It has since been suggested that these small detrital particles may be created by biological processes, including phytoplankton and bacterial growth, protozoan egestion of picofecal pellets, and/or viral lysis of bacteria [Koike et al., 1990; Sieracki and Viles, 1992; Nagata and Kirchman, 1996; Shibata et al., 1997; Yamasaki et al., 1998], and by physical forces contributing to disaggregation, flocculation, and adsorption on surfaces (see citations given by Stramski and Kiefer [1991], reviewed by Nagata and Kirchman [1996]). In addition to submicron detrital particles, a second group of particles of high refractive index (i.e., minerals) have been suggested to be important determinants of $b_{b}$ in the ocean, on the basis of numerous studies using Mie-modeled particle optical properties [Brown and Gordon, 1973; Zaneveld et al., 1974; Stramski et al., 2001; Twardowski et al., 2001]. Sources of mineral particles likely include the large-scale aeolian transport of atmospheric dust, sediment resuspension in coastal regions, and biogenic inputs such as calcite and silica from phytoplankton shells. More recently, we have suggested that both small detritus and mineral particles can be important and seasonally variable contributors to $b_{b}$ in New England shelf waters [Green et al., 2003b].

[4] Progress in understanding how different seawater constituents contribute to AOPs can be made with simulations that use radiative transfer theory. With the numerical radiative transfer model implemented in the Hydrolight software package, Mobley and Stramski [1997] demonstrated that inputs of the optical properties of individual microbial components, rather than just the total absorption and scattering properties of the water body, can be used to analyze the effects of the various particulate components on quantities such as $K_{d}$ and $R_{\mathrm{rs}}$. Their simulations were based on a database of singleparticle optical properties [Stramski and Mobley, 1997] and idealized particle concentrations. In considering ocean color models, they showed that different microbial compositions in two water bodies can give considerably different optical properties, even for the same chlorophyll concentrations. Similarly, measurements in the ocean of $R_{\mathrm{rs}}$ and [Chl] have shown that different $R_{\mathrm{rs}}$ can correspond to the same chlorophyll value [e.g., Clark, 1981]. These results emphasize that improved algorithms for the interpretation of ocean color signals depend on better information on individual seawater constituents and their contributions to optical properties in different oceanic regimes.

[5] Our goal in this study was to use detailed measurements of seawater constituents to identify the sources of variability in AOPs and sources of uncertainty in biooptical models. We interpreted seasonal variability in AOPs in New England shelf waters using Hydrolight and IOP measurements collected during the Coastal Mixing and Optics experiment. During this experiment, we intensively sampled individual particle and bulk optical properties at a site on the New England continental shelf during summer and spring. On the basis of the relationship between $b$ by particles $\left(b_{p}\right)$ and [Chl] (upper bound for Case 1 specified by $b_{p}(550)=0.78[\mathrm{Chl}]^{0.80}[$ Loisel and Morel, 1998]), each of the three spring and summer examples presented in this paper represented Case 1 waters. In our analysis, we constrained the IOPs of optically important seawater constituents, including water, chromophoric dissolved organic matter (CDOM), eukaryotic pico/nanophytoplankton, Synechococcus, heterotrophic prokaryotes, detritus, and minerals. We checked the consistency of our analysis by comparing modeled AOPs (from radiative transfer theory and constituent IOPs) with measured AOPs, and then we determined sources of seasonal variability in $K_{d}$ and $R_{\mathrm{rs}}$. Finally, we evaluated which constituents caused differences in bio-optical relationships between the waters we sampled and those previously described for typical open ocean conditions.

\section{Methods}

[6] Vertical profiles for water sampling and measurements of optical properties were made as part of the Coastal Mixing and Optics experiment as described by Sosik et al. [2001]. The site was located on the southern New England 
shelf, south of Martha's Vineyard $\left(40^{\circ} 30^{\prime} \mathrm{N}, 70^{\circ} 30^{\prime} \mathrm{W}\right)$, at a water depth of $\sim 70 \mathrm{~m}$. Data were collected during two 3-week cruises in the late summer of 1996 aboard the R/V Seward Johnson (cruise SJ9610, 17 August to 7 September) and spring of 1997 aboard the R/V Knorr (cruise KN150, 24 April to 13 May). All data presented here was collected within 2 hours of local noon.

\subsection{Bulk Optical Measurements}

[7] Bulk IOPs were measured during in situ profiles and in the laboratory on discrete water samples (for details, see Sosik et al. [2001]). Total absorption $\left(a_{\text {total }}\right)$, CDOM absorption $\left(a_{\mathrm{CDOM}}\right)$, and particulate absorption $\left(a_{p}\right)$ coefficients were measured in situ using absorption and attenuation meters (ac-9, WetLabs, Inc.) to measure unfiltered and filtered $(<0.2 \mu \mathrm{m})$ seawater in nine spectral bands $(412,440,488,510,532,555,650,676$, and $715 \mathrm{~nm})$. Additionally, optical measurements (i.e., spectrophotometry and flow cytometry) were made aboard ship on water samples collected from six depths throughout the water column with a conductivity-temperature-depth profiler/ rosette system equipped with sampling bottles. Absorption coefficients for particles collected on GF/F filters (Whatman, nominal pore size of $0.7 \mu \mathrm{m}$ ) were determined spectrophotometrically (using a Cary 3E dual beam UV/ visible spectrophotometer). Subsequent to the initial optical density measurements (used to determine $a_{p}$ ), filters were extracted in methanol and reanalyzed to determine the residual particulate absorption $\left(a_{\mathrm{dm}}\right.$; detritus + minerals $)$ [e.g., Kishino et al., 1985]. Measurements of chlorophyll a and phaeopigment concentrations were made on discrete samples by collecting material on $\mathrm{GF} / \mathrm{F}$ filters, extracting for 24 hours in cold $90 \%$ acetone, and measuring fluorometrically using a Turner Designs Model 10 fluorometer calibrated spectrophotometrically with pure chlorophyll $a$ (Sigma Chemical Co.).

[8] We determined AOPs from measurements with a tethered free-fall spectral radiometer (SPMR system, Satlantic, Inc.) that has seven spectral bands $(412,443,490$, $510,555,665$, and $683 \mathrm{~nm}$; bandwidth, $10 \mathrm{~nm}$ ) (for details, see Sosik et al. [2001]). The SPMR system consisted of a profiler that measures downwelling irradiance $\left(E_{d}\right)$, upwelling radiance $\left(L_{u}\right)$, conductivity, temperature, pressure, and instrument tilt, as well as a reference sensor that was suspended just below the water surface $(30 \mathrm{~cm}$ depth) and measured spectral $E_{d}$. Data from the spectral radiometers were processed using software provided by the manufacturer (ProSoft version 3.5d). All casts were edited to remove bad data at the top and bottom of the water column, which could be recognized by high tilt and low velocity of the profiler; typically the top 5-6 $\mathrm{m}$ of data were eliminated from profiles on the basis of these criteria. Results were then calibrated and averaged to 1-m bins over depth (z). Depthdependent diffuse attenuation coefficients for downwelling irradiance, $K_{d}$, were computed for each wavelength as [Smith and Baker, 1984, 1986]

$$
K_{d}(\lambda)=\frac{-d\left\{\ln \left[E_{d}(\mathrm{z})\right]\right\}}{d z}
$$

over 8 1-m depth bins; diffuse attenuation coefficients for upwelling radiance $\left(K_{u}\right)$ were computed in an analogous manner with $L_{u}$ substituted for $E_{d}$. Remote sensing reflectance, $R_{\mathrm{rs}}$, was estimated as the ratio of $L_{u}$ to $E_{d}$ just above the sea surface $\left(\mathrm{z}=0^{+}\right)$,

$$
R_{r s}(\lambda)=\frac{L_{u}\left(0^{+}, \lambda\right)}{E_{d}\left(0^{+}, \lambda\right)} ;
$$

values at $\mathrm{z}=0^{+}$were estimated by extrapolating from the top of the measured vertical $L_{u}$ and $E_{d}$ profiles to $\mathrm{z}=0^{-}$ with the shallowest $K_{d}$ and $K_{u}$ estimates available for each cast, and then using air-sea transfer functions for $E_{d}$ and $L_{u}$ to estimate above water values from propagated subsurface values; the air-sea transfer functions were determined from Hydrolight accounting for time of day and sea state (see below). $R_{\mathrm{rs}}$ calculated using Hydrolight-determined air-sea transfer functions differed by $\leq 2 \%$ from $R_{\mathrm{rs}}$ calculated assuming Fresnel reflectance for the sea surface of 0.021 for $L_{u}$ and 0.043 for $E_{d}$ [Gordon et al., 1988; Mueller and Austin, 1995; Sosik et al., 2001]. We chose to represent the uncertainties for $K_{d}$ and $R_{\mathrm{rs}}$ as the average of standard deviations in SPMR measurements collected on the same day (considering both cruises). This approach resulted in a standard deviation for $K_{d}$ of $0.0152 \mathrm{~m}^{-1}$ and for $R_{\mathrm{rs}}$ of $4.41 \times 10^{-4} \mathrm{sr}^{-1}$.

\subsection{Individual Particle Measurements and Theory}

[9] We calculated particle contributions to IOPs by summing contributions from particles of $0.1-50 \mu \mathrm{m}$ in diameter as detailed by Green et al. [2003b]. We summarize the approach only briefly here. Particles measured in water samples using flow cytometry were grouped into five categories: eukaryotic pico/nanophytoplankton ("eukaryotic phytoplankton"), Synechococcus, heterotrophic prokaryotes (bacteria plus archaea), detritus, and minerals. For particles of $\leq 10 \mu \mathrm{m}$ in diameter, a combination of flow cytometric (FCM) measurements and Mie theory was used to determine particle diameter, complex refractive index $\left(n+i n^{\prime}\right)$, and optical cross-sections for absorption $\left(\sigma_{a}\right)$, scattering $\left(\sigma_{b}\right)$, and backscattering $\left(\sigma_{b b}\right)$ at $488 \mathrm{~nm}$ (referred to as the "FCM-Mie" method [Green et al., 2003a]). Inherent in Mie theory are the assumptions that particles are spherical and homogenous, and our approach includes some corrections to account for violations of these for natural particles (i.e., empirical scattering corrections were applied for phytoplankton [Green et al., 2003a]). We defined detritus (organic particles) as non-phytoplankton with $n \leq 1.10$ and minerals as non-phytoplankton with $n>$ 1.10 , which may include inorganic particles, organic complexes, and/or organic particles with low water content [Aas, 1996]. All refractive indices are reported relative to seawater, for which $n=1.339$ relative to a vacuum. For small detritus $(0.1-1.2 \mu \mathrm{m})$ and minerals $(0.1-0.75 \mu \mathrm{m})$, size distributions were extrapolated to $0.1 \mu \mathrm{m}$ for each sample to estimate the contributions of these submicron particles to $b$ and $b_{b}$ (as discussed below, spectrophotometric values were used for $\left.a_{\mathrm{dm}}\right)$. Individual non-phytoplankton size distributions were described by a Junge-type model (or hyperbolic fit), and a segmented fit with two different slopes, above and below $3.5 \mu \mathrm{m}$, was used. Furthermore, we estimated the optical properties of eukaryotic phytoplankton, detritus, and minerals in the 10 to $50 \mu \mathrm{m}$ diameter range with a combination of Mie theory and empirical use 
of FCM measurements to estimate diameter. Particle sum contributions to $a, b$, and $b_{b}$ at $488 \mathrm{~nm}$ were calculated by summing over the optical cross-sections, $\sigma_{a}, \sigma_{b}$, and $\sigma_{b b}$, of all particles $(0.1-50 \mu \mathrm{m}$ in size) in a known volume.

\subsection{Radiative Transfer Modeling}

[10] We used the Hydrolight numerical model (version 4.1; Sequoia Scientific) to solve the radiative transfer equation and to generate values of $K_{d}$ and $R_{\mathrm{rs}}$. We applied the model to three examples from each season that exemplify within and between season differences in optical properties. The percent cloud cover and wind speed for each example were as follows: August 20, 10\%, $0.6 \mathrm{~m} \mathrm{~s}^{-1}$; August 22, 100\%, $4.8 \mathrm{~m} \mathrm{~s}^{-1}$; August $26,0 \%, 5.2 \mathrm{~m} \mathrm{~s}^{-1}$; April 30, 0\%, 6.2 $\mathrm{m} \mathrm{s}^{-1}$; May 6, 90\%, $12.9 \mathrm{~m} \mathrm{~s}^{-1}$; and May $9,100 \%, 5.1 \mathrm{~m} \mathrm{~s}^{-1}$. Additional user-defined inputs to Hydrolight include sea surface and bottom boundary conditions and the spectral IOPs of the water [Mobley, 1994; Mobley and Stramski, 1997]. For all calculations, we used a semi-empirical sky model (irradiances from Gregg and Carder [1990] and radiances from Harrison and Coombes [1988]) and a bottom depth of $70 \mathrm{~m}$. Other boundary conditions were given the specific values for each example, including percent cloud cover, wind speed, and solar zenith angle. CDOM fluorescence and Raman scattering were included for each example. In Hydrolight these inelastic scattering properties are determined as described by Mobley [1994], with CDOM fluorescence dependent on the fluorescence efficiency results of Hawes [1992] and our input of ac- $9 a_{\mathrm{CDOM}}$ measurements. Calculations were made at $412,443,490,510$, and $555 \mathrm{~nm}$ and at depth intervals of $10 \mathrm{~m}$. Modeling was not extended to the highest wavelengths in the SPMR measurements (i.e., 665 and $683 \mathrm{~nm}$ ), because the effects of chlorophyll fluorescence were not included in our Hydrolight simulations.

[11] We specified spectral $a, b$, and $b_{b}$ for input to Hydrolight. Spectral $b$ and $b_{b}$ for particles were used to determine the phase function in Hydrolight according to the backscattering fraction, with a Fournier-Fourand phase function [Fournier and Jonasz, 1999; Fournier and Forand, 1994; Mobley et al., 2002]. Values of IOPs were specified for the top $20 \mathrm{~m}$ of the water column (at 1, 10, and $20 \mathrm{~m}$ depth) and not below this depth, because our goal was to model AOPs for surface waters and the IOPs for depths below $20 \mathrm{~m}$ had little effect on modeled surface AOPs.

[12] Total IOPs for our Hydrolight calculations were defined as sums over the constituents of a natural sample. We specified the total spectral absorption coefficient, $a_{\text {total }}(\lambda)$, as a sum of the absorption by each of the constituents: pure seawater $\left(a_{w}(\lambda)\right), \mathrm{CDOM}\left(a_{\mathrm{CDOM}}(\lambda)\right)$, eukaryotic phytoplankton $\left(a_{\text {euk }}(\lambda)\right)$, Synechococcus $\left(a_{\text {syn }}(\lambda)\right)$, heterotrophic prokaryotes $\left(a_{\text {het }}(\lambda)\right)$, and non-phytoplankton particles $\left(a_{\mathrm{dm}}(\lambda)\right.$; detritus + minerals $)$, i.e.,

$$
\begin{aligned}
a_{\text {total }}(\lambda)= & a_{w}(\lambda)+a_{C D O M}(\lambda)+a_{\text {euk }}(\lambda)+a_{\text {syn }}(\lambda)+a_{\text {het }}(\lambda) \\
& +a_{\text {dm }}(\lambda) .
\end{aligned}
$$

Values of $a_{w}(\lambda)$ (assumed constant) were taken from Pope and Fry [1997], and $a_{\mathrm{CDOM}}$ was determined from the filtered ac-9. Similarly, we specified the total scattering and backscattering coefficients, $b_{\text {total }}(\lambda)$ and $b_{b \text {,total }}(\lambda)$, as sums of the contributions by pure seawater and each particle group,

$$
\begin{aligned}
b_{\text {total }}(\lambda)= & b_{w}(\lambda)+b_{\text {euk }}(\lambda)+b_{\text {syn }}(\lambda)+b_{\text {het }}(\lambda)+b_{\text {det }}(\lambda) \\
& +b_{\min }(\lambda)
\end{aligned}
$$

$$
\begin{aligned}
b_{b, \text { total }}(\lambda)= & b_{b, w}(\lambda)+b_{b, e u k}(\lambda)+b_{b, s y n}(\lambda)+b_{b, \text { het }}(\lambda)+b_{b, \operatorname{det}}(\lambda) \\
& +b_{b, \min }(\lambda)
\end{aligned}
$$

where the subscripts "det" and "min" refer to detritus and minerals, respectively. Values of $b_{w}(\lambda)$ were taken from Morel [1974], and $b_{b, w}(\lambda)$ was assumed to be half of $b_{w}(\lambda)$. We chose not to include bubbles in our IOP budgets, because they were most likely not major contributors. This assumption is based on the results of Stramski et al. [2001], who showed that bubbles are not expected to influence $a$, and may be only minor contributors to $b(5-10 \%)$ and $b_{b}$ $(4-7 \%)$ in open ocean waters. Even in coastal waters, high bubble densities are usually associated with breaking waves at high wind speeds [Terrill et al., 2001; Zhang et al., 2002], and our sampling was generally conducted under calm conditions.

[13] We estimated the spectral contributions of particles to IOPs from properties at $488 \mathrm{~nm}$ (the FCM laser wavelength) combined with Mie theory. For each particle group, inputs to Mie theory included the particle size distribution from 0.1 to $50 \mu \mathrm{m}$, a wavelength-independent $n$ equal to the FCM-Mie mean $n$ for each particle group, and a wavelength-dependent $n^{\prime}$. Mean values of $n^{\prime}$ at $488 \mathrm{~nm}$ for eukaryotic phytoplankton and Synechococcus were determined from the FCM-Mie method, and the value of $n^{\prime}$ at $488 \mathrm{~nm}$ for detritus and minerals was assumed to be $1 \times$ $10^{-3}$ [Green et al., 2003b]. Spectral $n^{\prime}$ for phytoplankton and non-phytoplankton was calculated as the product of FCM-Mie $n^{\prime}(488)$ and average spectrophotometric measurements of $a_{\mathrm{ph}}(\lambda) / a_{\mathrm{ph}}(488)$ and $a_{\mathrm{dm}}(\lambda) / a_{\mathrm{dm}}(488)$ for the depth range of $0-20 \mathrm{~m}$ [Sosik et al., 2001]. Spectral $n^{\prime}$ for heterotrophic prokaryotes was assumed equal to values presented by Stramski and Mobley [1997]. Total $a, b$, and $b_{b}$ for each particle group was calculated using the above inputs to Mie theory, with the exception of values for $a_{\mathrm{dm}}$, for which spectrophotometric measurements were used [Green et al., 2003b]. Spectrophotometric $a_{\mathrm{dm}}$ accounts for particles $>0.7 \mu \mathrm{m}$ in size, which leaves the $<0.7-\mu \mathrm{m}$ non-phytoplankton unconstrained. For lack of information regarding the absorption properties of submicron nonphytoplankton, we assumed $a_{\mathrm{dm}}$ between 0.1 and $0.7 \mu \mathrm{m}$ was negligible.

[14] Standard deviations were determined for modeled values of $K_{d}$ and $R_{\mathrm{rs}}$ from estimated errors in the IOPs from which they were determined. Uncertainties in IOPs were estimated as follows. We represented the uncertainty in $a_{\mathrm{ph}}$ as the average standard deviation between spectrophotometric and FCM-Mie values $\left(0.0048 \mathrm{~m}^{-1}\right.$ [Green et al., 2003b]). On the basis of results of Pegau et al. [1995], we assumed a coefficient of variation of $20 \%$ for $a_{\text {CDOM. For }}$ $a_{\mathrm{dm}}$, uncertainties were calculated as the standard deviation between spectrophotometric measurements from the two closest sampling times to noon for a given day. For $b_{b}$, 
we compared the extrapolation of submicron detritus and minerals determined from a Junge-type fit to particles $<3.5 \mu \mathrm{m}$ in size (as used in this paper) to a fit to particles $<2.1 \mu \mathrm{m}$ in size (an alternative approach; for details see Green et al. [2003b]). Standard deviations for $K_{d}$ and $R_{\mathrm{rs}}$ were determined with methods of error propagation and the equations $K_{d}=\mathrm{x} 1\left(a+b_{b}\right)$ and $R_{\mathrm{rs}}=\times 2\left(b_{b} / a\right)$, where $\mathrm{x} 1$ and $\mathrm{x} 2$ were treated as wavelength-dependent constants that we determined exactly from modeled $K_{d}$ and $R_{\mathrm{rs}}$ for each example.

\subsection{Bio-Optical Models}

[15] A variety of inversion models exist for predicting [Chl] and IOPs from reflectance. We focused on semianalytical ocean color models since our data set is well suited to testing the assumptions and parameterizations of these models. We applied the two-band semianalytical model of Morel and Maritorena [2001] (henceforth referred to as the MM model) for determining [Chl] from irradiance reflectance $(R)$ at two wavelengths $(R(443) / R(555))$, where

$$
R(\lambda)=\frac{E_{u}\left(0^{-}, \lambda\right)}{E_{d}\left(0^{-}, \lambda\right)}
$$

We converted our measured $R_{\mathrm{rs}}$ to $R$ by multiplying by the factor Q where

$$
Q(\lambda)=\frac{E_{u}(\lambda)}{L_{u}(\lambda)}
$$

Values of $Q$ were obtained from our Hydrolight simulations and were between 3.4 and 3.9, within the range of 3-6 reported by Morel and Gentili [1993]. As well, we tested the semianalytical Garver-Siegel-Maritorena (GSM01) model [Maritorena et al., 2002; Garver and Siegel, 1997], which is based on a spectral optimization approach and retrieves [Chl], $a_{\mathrm{cdm}}(443)$, and $b_{b, p}(443)$. Both the MM and GSM01 models were developed for application to Case 1 waters. The GSM01 model relies on the parameterization of $a_{\mathrm{dm}}$ and $a_{\mathrm{CDOM}}$ as their sum $a_{\mathrm{cdm}}=a_{\mathrm{dm}}+a_{\mathrm{CDOM}}$. Each semianalytical model uses some or all (depending on the model) of the following parameterizations for $a_{\mathrm{cdm}}(\lambda)$, $b_{b, p}(\lambda)$, and below-surface remote sensing reflectance $\left(r_{\mathrm{rs}}(\lambda)\right)$ :

$$
\begin{gathered}
a_{c d m}(\lambda)=a_{c d m}\left(\lambda_{0}\right) \exp \left[-S\left(\lambda-\lambda_{0}\right)\right], \\
b_{b, p}(\lambda)=b_{b, p}\left(\lambda_{0}\right)\left(\frac{\lambda_{0}}{\lambda}\right)^{Y}, \\
r_{r s}(\lambda)=\frac{L_{u}\left(0^{-}\right)}{E_{d}\left(0^{-}\right)}=g_{1}\left(\frac{b_{b}}{a+b_{b}}\right)+g_{2}\left(\frac{b_{b}}{a+b_{b}}\right)^{2},
\end{gathered}
$$

where $S$ is the spectral slope for $a_{\mathrm{cdm}}, Y$ is the spectral power law exponent for $b_{b, p}, \lambda_{0}$ is a reference wavelength, and $g_{1}$ and $g_{2}$ are constants (0.0949 and 0.0794, respectively [Gordon et al., 1988]). For comparison, we also determined [Chl] from the current algorithm used for Sea-viewing Wide Field-of-view Sensor (SeaWiFS) global products (the
SeaBAM OC4 model [O'Reilly et al., 1998]); this algorithm is purely empirical and could not be used to retrieve IOPs.

\section{Results and Discussion}

[16] Our observations showed that spectral values of $K_{d}$ and $R_{\mathrm{rs}}$ were significantly different between the summer and spring, and our objective here is to analyze which constituent variations were responsible. In the following, we first provide context for our constituent analyses by discussing general differences between seasons observed in the bulk optical measurements. We then present the spectral IOPs of individual seawater constituents for each season and use their properties to explain variability in AOPs. Finally, we explore which constituents cause deviations from semianalytical ocean color models developed for oceanic Case 1 waters.

\subsection{Overview: Spectral Variations in Measured $\boldsymbol{K}_{\boldsymbol{d}}$ and $\boldsymbol{R}_{\mathrm{rs}}$}

[17] Differences in the magnitude and spectral shape of near-surface $(<15 \mathrm{~m}) K_{d}$ were evident between the seasons. At blue and green wavelengths, mean $K_{d}$ values in surface waters were higher in the spring (Figures 1a-1c). Because $K_{d}$ is highly dependent on absorption, an initial interpretation of variability in $K_{d}$ can be made by examining bulk absorption coefficients from ac-9 measurements. Higher $a_{\text {total }}$ in the spring was consistent with values of $K_{d}$ that were larger than in the summer at all wavelengths. Compared to summer, spring surface waters had chlorophyll concentrations that were $\sim 4 x$ higher (mean of $1.8 \mathrm{mg}$ $\mathrm{m}^{-3}$ versus $0.50 \mathrm{mg} \mathrm{m}^{-3}$ ) and particulate absorption, $a_{p}(440)$, that was $\sim 2 \mathrm{x}$ higher (mean of $0.085 \mathrm{~m}^{-1}$ versus $\left.0.035 \mathrm{~m}^{-1}\right)$. Considering all observations made in each season, the standard deviations for $K_{d}$ were also higher in the spring, due to more variability in $a_{\text {total }}$ in spring surface waters than in the summer. Absorption was less variable in summer surface waters, associated with a highly stratified water column that had low nutrient levels in the mixed layer and elevated phytoplankton concentrations mid-water column but not in surface waters [Sosik et al., 2001]. In comparison, during the spring, the water column was relatively well mixed, nutrient levels were high in surface waters, and the onset of stratification was associated with a near-surface phytoplankton bloom. On April 30 (lowest spring $K_{d}$ ) the water column was well mixed compared to on May 6 and 9, which followed the onset of stratification (Figure 1c). May 6 (highest spring $K_{d}$ ) showed peak chlorophyll concentrations in surface waters, and by May 9, chlorophyll concentrations had begun to decrease again. There was a small but significant spectral shift toward enhanced blue relative to green attenuation in spring compared to summer ( $p \ll 0.001$, t-test). The ratio $K_{d}(443) / K_{d}(555)$ had a mean value of 1.20 in the summer and 1.43 in the spring as reported by Sosik et al. [2001].

[18] We also observed differences in the magnitude and spectral shape of $R_{\mathrm{rs}}$ between the seasons. In the spring, surface waters were generally darker and greener, exemplified by $R_{\mathrm{rs}}$ values that were lower at blue wavelengths but slightly higher at $555 \mathrm{~nm}$ compared to the summer 

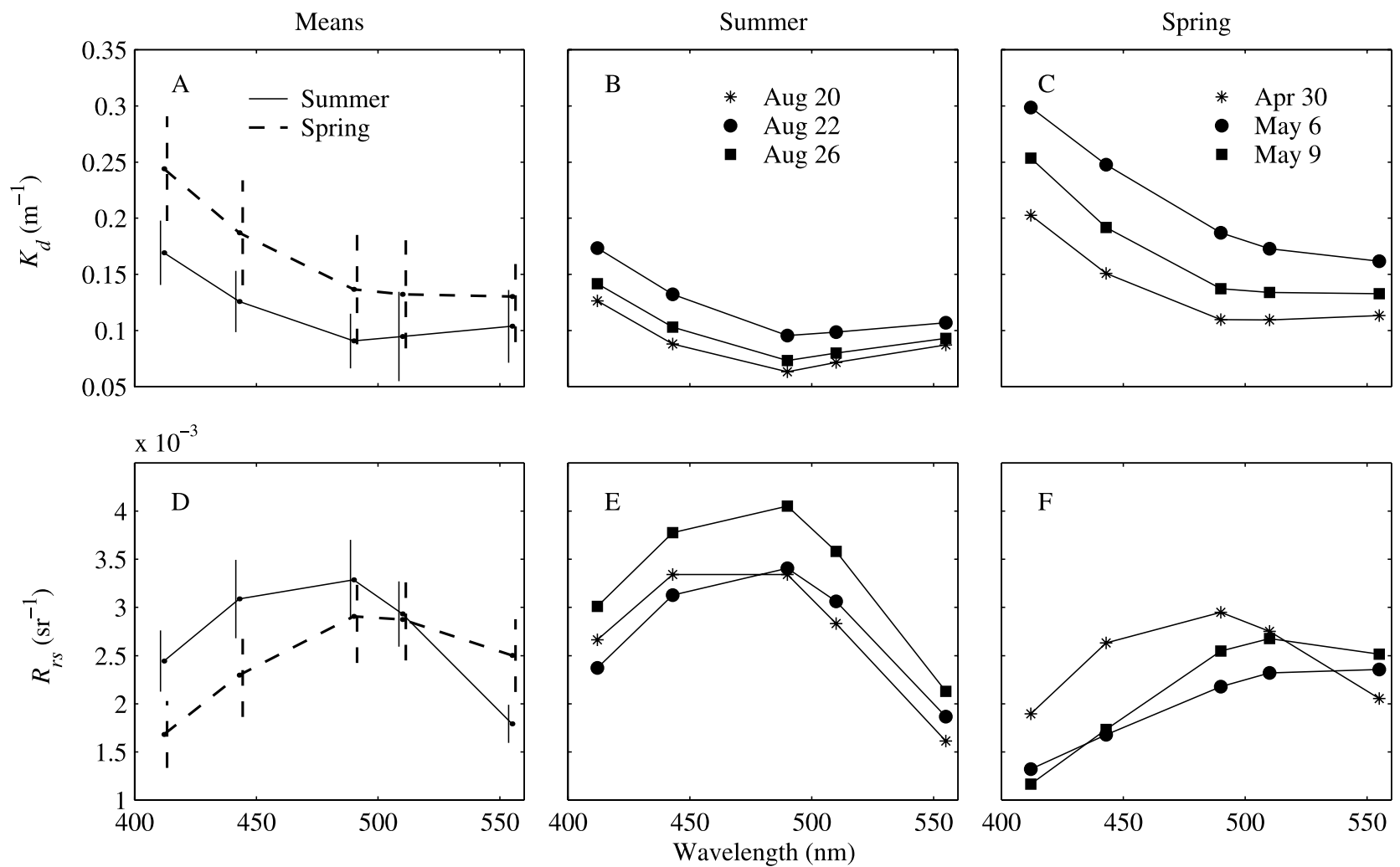

Figure 1. Measured near-surface $(<15 \mathrm{~m})$ values of $K_{d}$ (a) spectral means for each season, (b) summer spectra, and (c) spring spectra, and measured values of $R_{\mathrm{rs}}(\mathrm{d})$ spectral means for each season, (e) summer spectra, and (f) spring spectra. Standard deviations are plotted for each mean spectrum as a measure of the variability observed during the sampling period. Three example spectra were chosen from each of the summer and spring sampling periods to exemplify within and between season differences in optical properties.

(Figures $1 \mathrm{~d}-1 \mathrm{f}$ ). Given that $R_{\mathrm{rs}}$ is determined primarily by the ratio $b_{b, \text { total }} / a_{\text {total }}$, it is difficult to make an initial interpretation of variability in $R_{\mathrm{rs}}$ from bulk optical measurements, because bulk backscattering was not available for either season. The mean value of the ratio $R_{\mathrm{rs}}(443) / R_{\mathrm{rs}}(555)$ was 1.62 in the summer and 0.90 in the spring [Sosik et al., 2001], and the standard deviation of this ratio was $\sim 2 \mathrm{x}$ higher in the spring. The greater variation observed in $R_{\mathrm{rs}}$ spectral shape in the spring was exemplified by the large differences among the April 30, May 6, and May 9 spectra (Figure 1f). Despite these spectral differences, $R_{\mathrm{rs}}(555)$ was always greater than $R_{\mathrm{rs}}(412)$ in the spring, whereas in the summer $R_{\mathrm{rs}}(555)$ was always less than $R_{\mathrm{rs}}(412)$.

\subsection{Constituent IOPS}

[19] Differences in the contributions of eukaryotic phytoplankton and CDOM were the main determinants of variability in $a_{\text {total }}$ between seasons (Figures $2 \mathrm{a}-2 \mathrm{f}$ ). Water was an important contributor to absorption in both seasons at wavelengths $\geq 488 \mathrm{~nm}$. Considering both seasons, $a_{\text {euk }}$ was the most variable contributor to $a_{\text {total }}$ but changes in $a_{\text {CDOM }}$ were also important. Values of $a_{\text {total }}$ were always higher in the spring than in the summer, due primarily to $a_{\text {euk }}$ which was $\sim 5 \mathrm{x}$ higher and secondarily to $a_{\mathrm{CDOM}}$ which was $\sim 1.5 \mathrm{x}$ higher. Values of $a_{\text {euk }}$ were maximal at $440 \mathrm{~nm}$ in all cases, as expected for phytoplankton [e.g.,
Sathyendranath et al., 1987]. In the summer examples, the contribution of $a_{\text {euk }}$ to $a_{\text {total }}$ decreased with time and was the lowest on August 26. In the spring, the contribution of $a_{\text {euk }}$ to $a_{\text {total }}$ increased following the onset of stratification and was the highest on May 6 when $a_{\text {euk }}$ was an important contributor to $a_{\text {total }}$ at all wavelengths. The $a_{\mathrm{CDOM}}$ decreased with increasing wavelength and was a larger fraction of $a_{\text {total }}$ in the summer when values of $a_{\text {total }}$ were lower. The absolute magnitude of $a_{\mathrm{CDOM}}$ was smaller in summer surface waters compared to the spring (mean $a_{\text {CDOM }}(412)=0.073 \mathrm{~m}^{-1}$ versus $0.11 \mathrm{~m}^{-1}$ ), however, most likely because of photooxidation of CDOM in summer surface waters as has previously been suggested for this region [Vodacek et al., 1997; Boss et al., 2001]. The $a_{\mathrm{dm}}$ contributions increased with decreasing wavelength, as expected for particulate detritus [e.g., Roesler et al., 1989], but even at $412 \mathrm{~nm}$ it contributed only $5-12 \%$ to $a_{\text {total }}$. The mean spectral slope, $S$, of $a_{\text {cdm }}$ was $0.015 \mathrm{~nm}^{-1}$ $\left( \pm 0.001 \mathrm{~nm}^{-1}\right)$, considering both seasons. The contributions of heterotrophic prokaryotes and Synechococcus to absorption were negligible in both seasons, with each group contributing $\leq 4 \%$ at all wavelengths.

[20] Eukaryotic phytoplankton were the most important contributor to $b_{\text {total }}$ in both seasons (Figures $3 \mathrm{a}-3 \mathrm{f}$ ). The $b_{\text {euk }}$ made up $45-69 \%$ of $b_{\text {total, }}$, considering both seasons and all wavelengths. The spectral shape of $b_{\text {euk }}$ was 

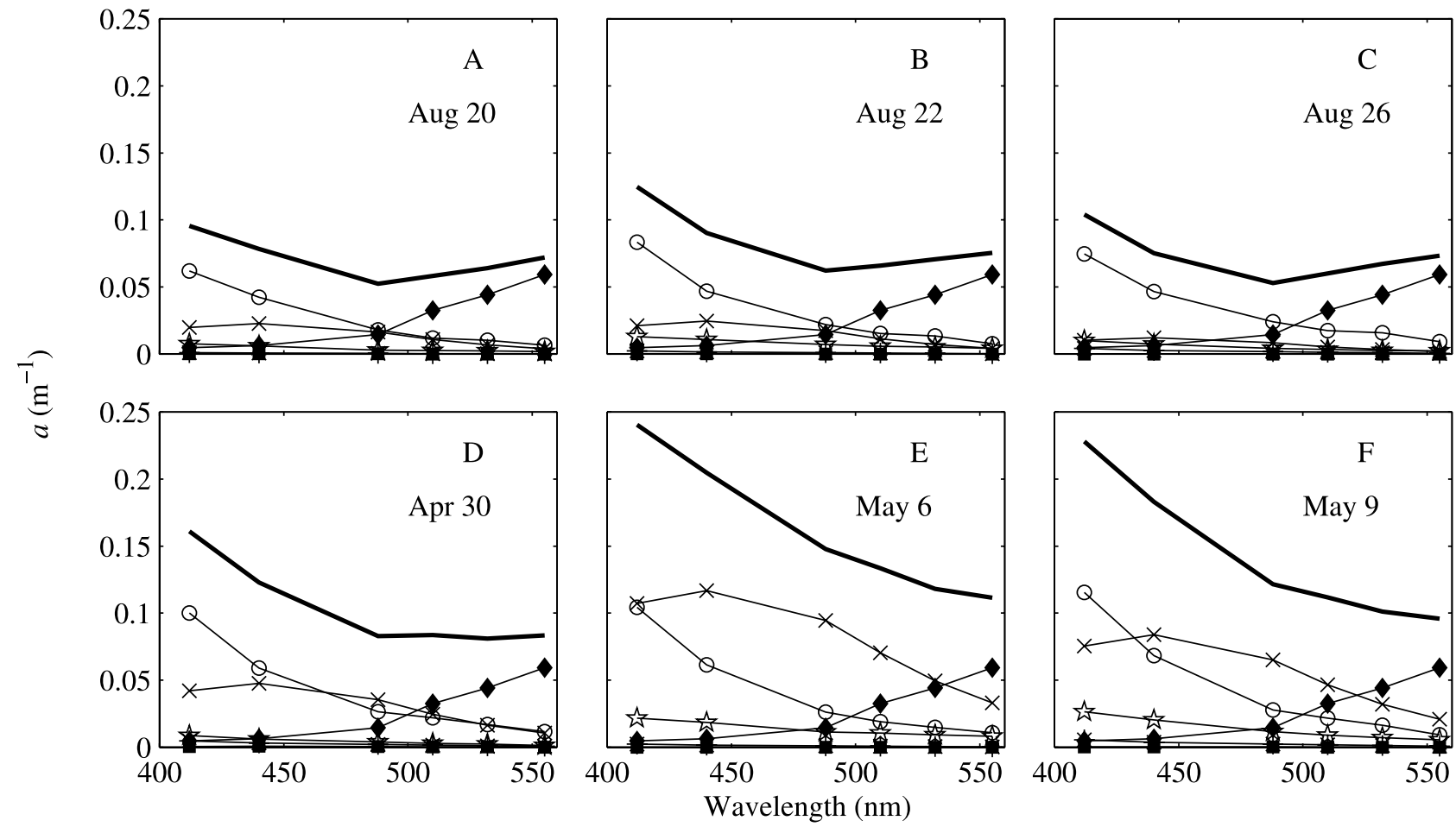

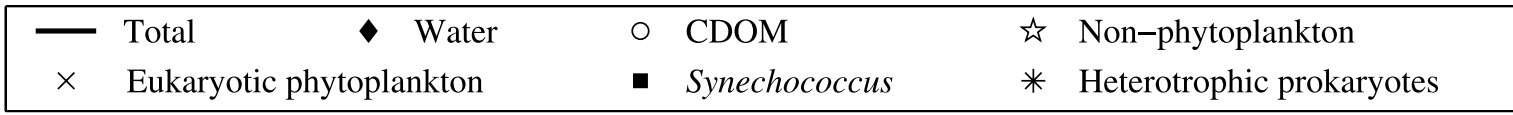

Figure 2. Total and constituent $a(\lambda)$ at $1 \mathrm{~m}$ depth for $(\mathrm{a}-\mathrm{c})$ each of the three summer examples and $(d-f)$ each of the three spring examples. Notably, there was a significant difference in absorption by eukaryotic phytoplankton, $a_{\text {euk }}$, between the two seasons.

generally the inverse of the spectral shape of $a_{\text {euk }}$, as expected from previous work [Ahn et al., 1992]. This was a direct outcome of the calculation of $b_{\text {euk }}$ from Mie theory using inputs of $n^{\prime}$ (with the spectral shape of $a_{\text {euk }}$ ) and $n$ (assumed spectrally constant). Minerals and heterotrophic prokaryotes each contributed $\sim 17 \%$ to $b_{\text {total }}$, considering both seasons and all wavelengths. Detritus contributed $\leq 5 \%$ to $b_{\text {total }}$, and Synechococcus and water each contributed $\leq 1 \%$.

[21] Differences in the contributions of detritus and minerals were the main determinants of variability in $b_{b \text {,total }}$ between seasons (Figures $4 \mathrm{a}-4 \mathrm{f}$ ). The magnitudes of $b_{b, \text { total }}$ were similar for both seasons, between 0.003 and $0.008 \mathrm{~m}^{-1}$, and were within the range of $0.001-0.02 \mathrm{~m}^{-1}$ previously reported for bulk optical measurements of natural samples [Stramski et al., 1999; Balch et al., 2001; Reynolds et al., 2001; Twardowski et al., 2001; Stramska et al., 2003]. The $b_{b \text {,total }}$ increased with decreasing wavelength, mainly due to the importance of $b_{b, w}$ at blue wavelengths. Water contributed $\sim 50 \%$ to $b_{b \text {,total }}$ at $412 \mathrm{~nm}$ and $\sim 24 \%$ to $b_{b \text {,total }}$ at $555 \mathrm{~nm}$ in both seasons. Detritus was more important in the summer than in the spring, contributing $20-35 \%$ to $b_{b \text {,total }}$ in the summer and $<1 \%$ in the spring, considering all wavelengths. Minerals were equal to or less important than detritus in the summer, contributing $14-38 \%$ to $b_{b \text {,total. }}$. In contrast, during the spring, minerals were the most important particulate contributor to $b_{b \text {,total }}$ and their contribution increased with time, from $30 \%$ to
$60 \%$. Spectral $b_{b \text {,det }}$ in the summer increased with decreasing wavelength, and spectral $b_{b, \min }$ in both the summer and spring was relatively flat. This contrasts with results of Stramski et al. [2001] where both $b_{b, \min }$ and $b_{b, \text { det }}$ increased with decreasing wavelength, likely due to differences in non-phytoplankton size distributions between our study and theirs. The contribution of heterotrophic prokaryotes to $b_{b, \text { total }}$ was variable ranging from $4 \%$ on August 20 to $17 \%$ on May 9 . This variability was caused by changes in concentration of heterotrophic prokaryotes with the highest concentrations on May $9\left(2.11 \times 10^{6} \mathrm{~mL}^{-1}\right)$ and lowest concentrations on August $20\left(3.44 \times 10^{5} \mathrm{~mL}^{-1}\right)$. The contribution to $b_{b}$ by phytoplankton was generally small with contributions to $b_{b \text {,total }}$ of $\leq 9 \%$ for eukaryotic phytoplankton and $<1 \%$ for Synechococcus.

[22] Differences in the size distributions of detritus and minerals caused the seasonal variability in our modeled values of $b_{b}$. On the basis of our extrapolated size distributions, detritus was an important contributor to $b_{b \text {,total }}$ in the summer, but not in the spring, because submicron detritus were more abundant in the summer (Figures $5 \mathrm{a}-5 \mathrm{~d}$ ). Submicron detritus contributed $94 \%$ to detrital backscattering, $b_{b \text {,det, }}$ in the summer. The importance of small detritus in the summer caused spectral $b_{b \text {,det }}$ and $b_{b, p}$ to increase with decreasing wavelength (Figures $4 \mathrm{a}-4 \mathrm{c}$ and $6 \mathrm{a}$ ); the mean power law exponent for $b_{b, p}, Y$, was $0.89( \pm 0.13)$ in the summer. In contrast to detritus, minerals were important contributors to $b_{b, p}$ in 


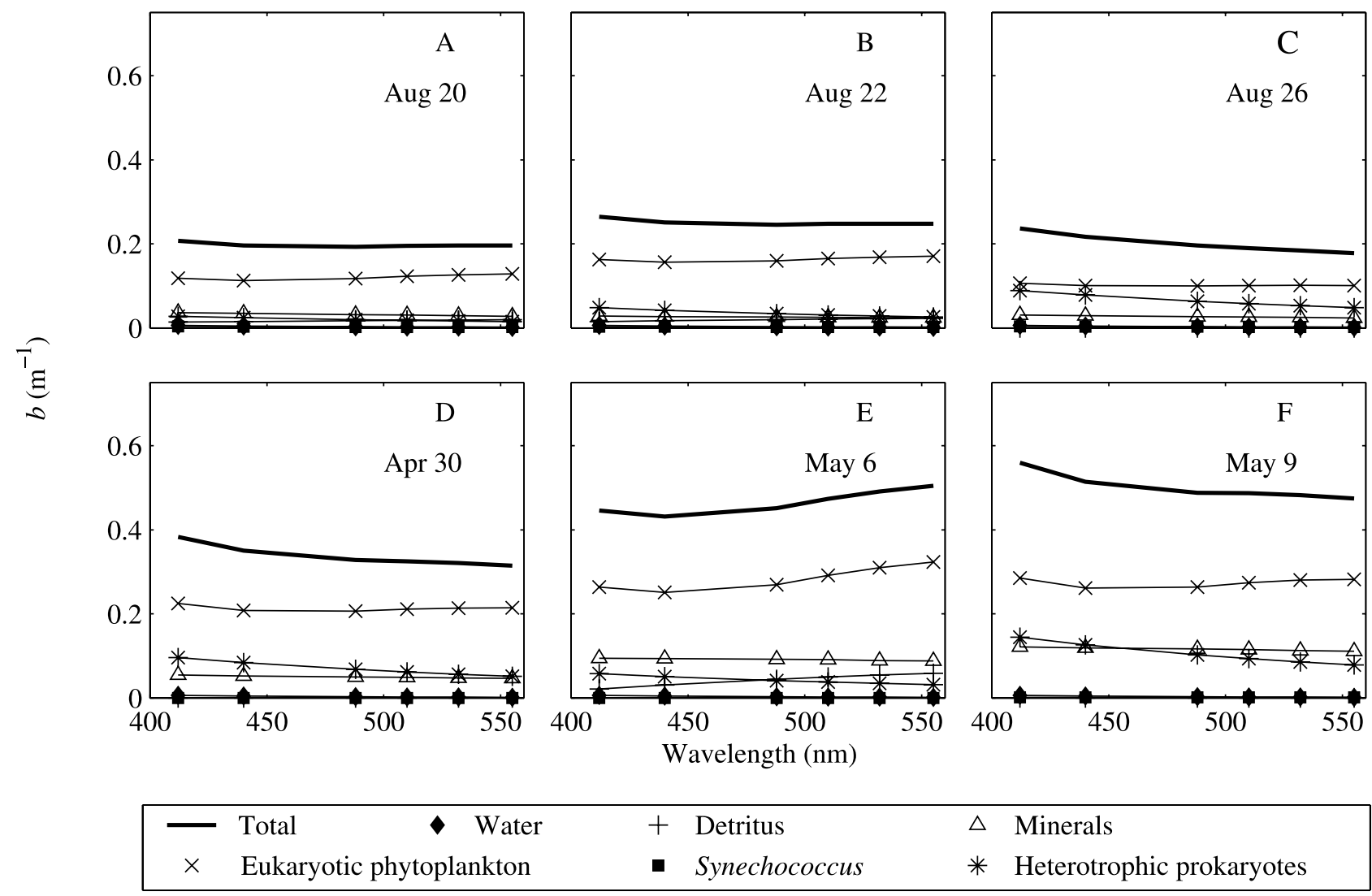

Figure 3. Total and constituent $b(\lambda)$ at $1 \mathrm{~m}$ depth for $(\mathrm{a}-\mathrm{c})$ each of the three summer examples and $(\mathrm{d}-\mathrm{f})$ each of the three spring examples. Eukaryotic phytoplankton were the most important contributors to $b_{\text {total }}$.

both seasons, due to the abundances and contributions of both submicron and larger minerals. Submicron minerals contributed $73 \%$ to $b_{b, \min }$ in the summer and $58 \%$ to $b_{b \text {, min }}$ in the spring. The contribution of large mineral particles was high enough, however, to cause the relatively flat spectral $b_{b \text {, min }}$ in both seasons (Figures $4 \mathrm{a}-4 \mathrm{f}$ ). In the spring, $b_{b, p}$ was relatively flat (Figure 6a) with a mean $Y$ equal to $-0.21( \pm 0.22)$. Higher backscattering ratios $\left(\widetilde{b_{b}}=b_{b, p} / b_{p}\right)$ were observed in the summer (Figure $6 b$ ) and were the result, not of differences in the magnitude of $b_{b, p}$, but of lower $b_{\text {total }}$ in the summer. This was mainly caused by lower values of $b_{\text {euk }}$ than in the spring. Higher summer values of $\widetilde{b_{b}}$ when chlorophyll concentrations were lower is consistent with previous findings of an inverse relationship between $\widetilde{b_{b}}$ and [Chl] [Sathyendranath et al., 1989; Ulloa et al., 1994; Twardowski et al., 2001]. In contrast to previous theoretical and experimental observations [Ulloa et al., 1994; Twardowski et al., 2001; Macdonald et al., 2000], our spectral $\widetilde{b_{b}}$ often displayed significant wavelength dependence, with slopes ranging from -0.65 to 0.89 .

\subsection{Comparison of Modeled and Measured $K_{d}$ and $\boldsymbol{R}_{\mathrm{rs}}$}

[23] For each of the example days, the spectral IOPs (Figures 2-4) were input to Hydrolight, along with the boundary conditions specified above, to compute spectra of $K_{d}$ and $R_{\mathrm{rs}}$. The modeled spectra were then compared to measured values to determine how well we could achieve closure on the basis of our constituent IOPs. We consider the ability to achieve closure between modeled and measured AOPs for our data set an important step in checking the consistency of our methodology and allowing us to explain variability in AOPs.

[24] Modeled values of $K_{d}$ compared well with measured values in both magnitude and spectral shape at $10 \mathrm{~m}$ depth (Figures $7 \mathrm{a}-7 \mathrm{f}$ ). Modeled values averaged 25\% higher than measurements in summer and 4\% lower than measurements in spring. The modeled and measured $K_{d}$ had similar spectral shapes. Values of $K_{d}(443) / K_{d}(555)$ were always higher in the summer than in the spring with mean ratios of 1.28 and 1.07 for modeled and measured values in the summer, respectively, and 1.54 and 1.43 for modeled and measured values in the spring, respectively. Modeled ratios of $K_{d}(443) / K_{d}(555)$ tended to be higher than measured values, possibly because our FCM-Mie method underestimated phytoplankton absorption by about $13 \%$ at $488 \mathrm{~nm}$ as reported by Green et al. [2003b].

[25] Modeled values of $R_{\mathrm{rs}}$ were similar to measured values of $R_{\mathrm{rs}}$ in both magnitude and spectral shape (Figures 8a-8f). In the summer, modeled values averaged $10 \%$ higher than measurements, and in the spring, modeled values averaged $7 \%$ lower than measurements. The modeled and measured $R_{\mathrm{rs}}$ had similar spectral shapes. Both exhibited higher values of $R_{\mathrm{rs}}(443) / R_{\mathrm{rs}}(555)$ in the summer than in the spring, with mean values $>1$ in the summer and $<1$ in the spring. Values of modeled and measured $R_{\mathrm{rs}}(443) /$ 


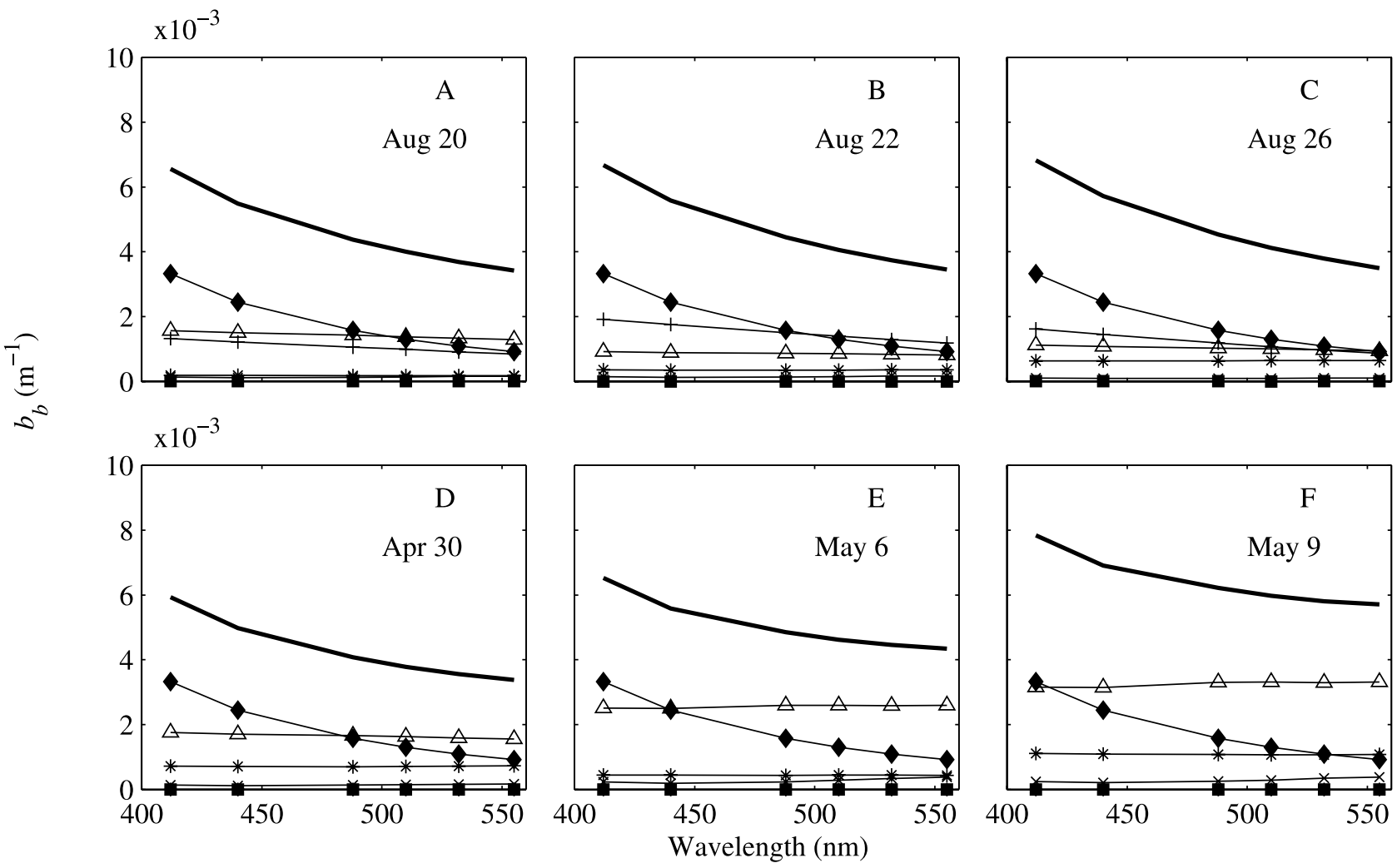

Figure 4. Total and constituent $b_{b}(\lambda)$ at $1 \mathrm{~m}$ depth for $(\mathrm{a}-\mathrm{c})$ each of the three summer examples and $(\mathrm{d}-\mathrm{f})$ each of the three spring examples. Minerals and detritus were the most important particulate contributors to $b_{b \text {,total }}$ in the summer, in comparison to the spring during which minerals were most important. The legend is the same as in Figure 3.

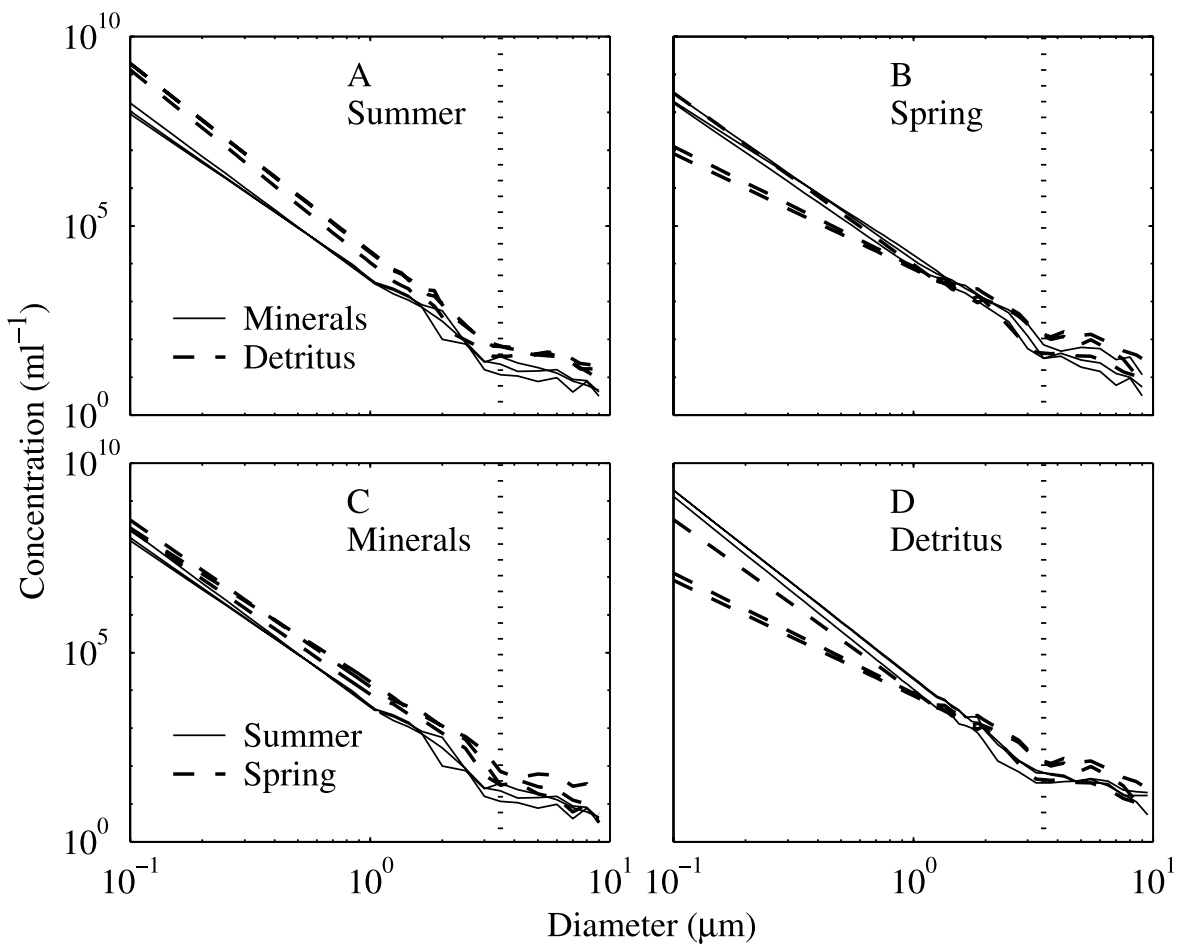

Figure 5. Size distributions of detritus and minerals for the (a) summer examples and (b) spring examples, and size distributions for both seasons of (c) minerals and (d) detritus. Total size distributions contain the portion determined from the FCM-Mie method and the portion extrapolated using the $<3.5 \mu \mathrm{m}$ Junge slopes according to Green et al. [2003b]. Note that the slope for $<3.5 \mu \mathrm{m}$ detritus on April 30 was higher than on May 6 and May 9 but was not as high as in the summer. 

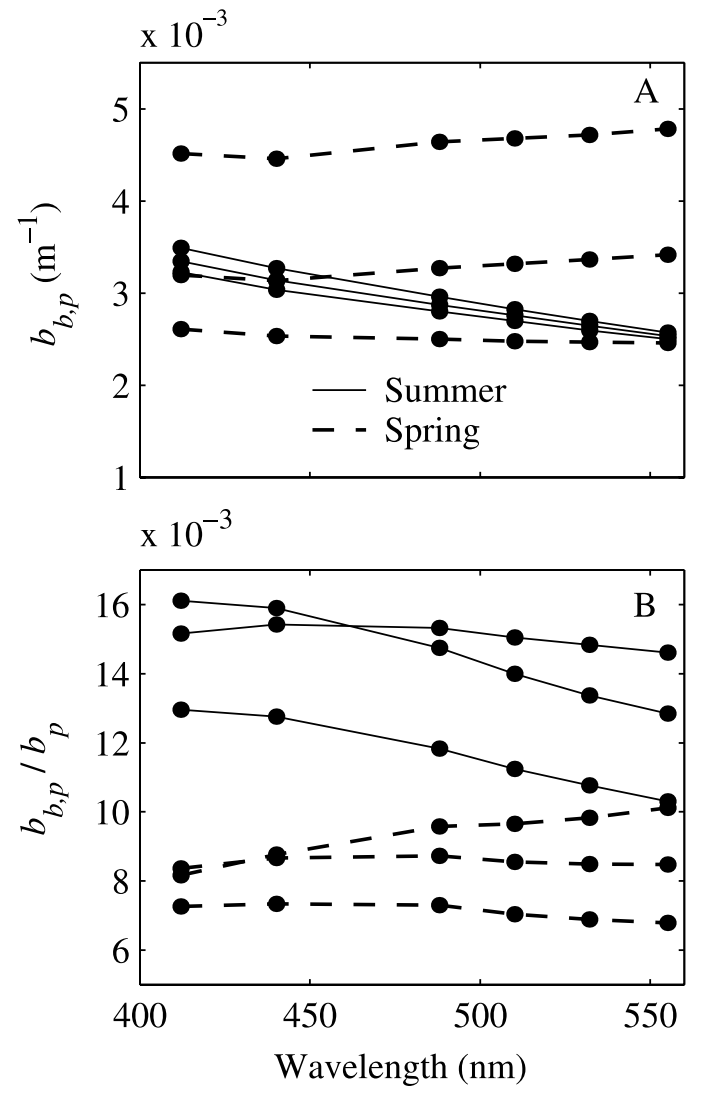

Figure 6. Summer and spring spectra of (a) $b_{b, p}$, and (b) $b_{b, p} / b_{p}$. Steeper negative slopes of $b_{b, p}$ were caused by size distributions with relatively more small particles, as occurred in the summer relative to the spring. Higher ratios of $b_{b, p} / b_{p}$ in the summer were caused primarily by lower values of $b_{p}$ in the summer.

$R_{\mathrm{rs}}(555)$ were 1.29 and 1.84 , respectively, in the summer and 0.77 and 0.90 , respectively, in the spring. The generally lower modeled ratios of $R_{\mathrm{rs}}$ compared to measured ratios, especially in the summer, might be attributed to underestimated values of $a_{\text {euk }}$ and/or to errors in the estimates of backscattering by small detrital and mineral particles. As well, the extrapolation of measured $K_{d}$ and $R_{\mathrm{rs}}$ profiles to the surface from 5 or $6 \mathrm{~m}$ could contribute to differences between modeled and measured values. Standard deviations were the largest for modeled $R_{\mathrm{rs}}$ in the summer because of larger uncertainty in $b_{b}$. The agreement, within estimated uncertainties, between modeled and measured magnitudes and spectral shapes for both $R_{\mathrm{rs}}$ and $K_{d}$ gave us confidence in use of the Hydrolight analyses to further explore the sources of AOP variations.

\subsection{Sources of Variability in $K_{d}$ and $R_{\mathrm{rs}}$}

[26] Seasonal differences in $K_{d}$ were caused by variability in $a_{\text {euk }}$ and $a_{\mathrm{CDOM}}$. As discussed above, these two components were the most important contributors to variability in $a_{\text {total }}$. We quantified the roles of $a_{\text {euk }}$ and $a_{\text {CDOM }}$ in determining seasonal differences in $K_{d}$ by performing two Hydrolight substitution simulations for the spring examples: (1) with $a_{\text {euk }}$ replaced by mean summer values, and (2) with both $a_{\text {euk }}$ and $a_{\mathrm{CDOM}}$ replaced by mean summer values; in these simulations, all other absorption and scattering terms were fixed at the appropriate measured values. From this analysis, we found that the higher magnitude of $K_{d}$ at all wavelengths in the spring was caused primarily by higher values of $a_{\text {euk }}$ and secondarily by higher values of $a_{\mathrm{CDOM}}$ especially at $412 \mathrm{~nm}$ (Figure 9a). There was a spectral shift toward enhanced blue relative to green attenuation in the spring primarily because phytoplankton absorb more at blue than at green wavelengths. Substitution of the spring $a_{\text {euk }}$ by its mean summer value removed most of the difference in spectral shape between seasons, resulting in a ratio of $K_{d}(443) / K_{d}(555)$ in the spring of 1.31 , similar to the summer value of 1.28 .

[27] Variations in $K_{d}$ within the summer were caused by changes in both $a_{\text {euk }}$ and $a_{\mathrm{CDOM}}$, and variations during the spring were mainly caused by changes in $a_{\text {euk }}$. For the summer examples, values of $a_{\mathrm{CDOM}}$ and $a_{\text {euk }}$ were approximately equally variable, with standard deviations of $0.01 \mathrm{~m}^{-1}$ and $0.006 \mathrm{~m}^{-1}$, respectively, at $412 \mathrm{~nm}$. Variability in $a_{\mathrm{CDOM}}$ in the summer was most likely related to both the periodic intrusions of oceanic warm salty water, as occurred on August 22, and to vertical displacements of the pycnocline by Rossby or Kelvin waves as suggested by Boss et al. [2001]. In contrast to the summer, for the spring examples $a_{\mathrm{CDOM}}$ was less variable than $a_{\text {euk }}$, with standard deviations of $0.008 \mathrm{~m}^{-1}$ and $0.03 \mathrm{~m}^{-1}$, respectively, at $412 \mathrm{~nm}$. This lead to changes in spring $K_{d}$ that were directly related to changes in $a_{\text {euk }}$. For example, the highest values of spring $K_{d}$ occurred following the onset of stratification and corresponded to high values of $a_{\text {euk }}$ and chlorophyll concentration (Figures 2d-2f and 7d-7f) [Sosik et al., 2001].

[28] Seasonal differences in $R_{\mathrm{rs}}$ were caused by variability in constituent contributions to spectral $a$ and $b_{b}$. As described above, $a_{\text {euk }}, a_{\mathrm{CDOM}}, b_{b \text {, min }}$, and $b_{b \text {,det }}$ were the most important contributors to variability in $a_{\text {total }}$ and $b_{b \text {,total }}$. We quantified the roles of $a_{\text {euk }}, a_{\mathrm{CDOM}}, b_{b \text {,det }}$, and $b_{b, \text { min }}$ in determining seasonal variability in $R_{\mathrm{rs}}$ by performing three Hydrolight substitution simulations for the spring examples: (1) with $a_{\text {euk }}$ replaced by mean summer values, (2) with both $a_{\text {euk }}$ and $a_{\text {CDOM }}$ replaced by mean summer values, and (3) with $a_{\text {euk }}, a_{\mathrm{CDOM}}, b_{b \text {,det }}$, and $b_{b \text {, min }}$ all replaced by mean summer values. From this analysis, we found that the higher magnitude of $R_{\mathrm{rs}}$ in the summer was caused primarily by differences in $a_{\text {euk }}$ at wavelengths $\geq 490 \mathrm{~nm}$ and by the combined effects of $a_{\text {euk }}, a_{\mathrm{CDOM}}, b_{b \text {, det }}$, and $b_{b \text {, min }}$ at wavelengths $\leq 443 \mathrm{~nm}$ (Figure 9b), although the importance of $b_{b \text {,det }}$, and $b_{b \text {, min }}$ effects are difficult to assess given the relatively high uncertainty in estimates for modeled summer $R_{\mathrm{rs}}$ magnitude (Figure 8). Considering spectral shape, the substitutions resulted in ratios for $R_{\mathrm{rs}}(443) / R_{\mathrm{rs}}(555)$ of 0.98 , 1.12 , and 1.29 , respectively, corresponding to $40 \%, 27 \%$, and $33 \%$ of the difference between the spring ratio $(0.77)$ and the summer ratio (1.29) (Figure 9c). The ratio for the third simulation was the same as the summer value. Notably, higher values of both $a_{\text {euk }}$ and $a_{\mathrm{CDOM}}$ in the spring compared to summer were enough to account for a ratio of $R_{\mathrm{rs}}(443) / R_{\mathrm{rs}}(555)$ which was $<1$ in spring and $>1$ in summer. Spectral differences in particle backscattering, $b_{b, p}$, also contributed substantially to summer values of $R_{\mathrm{rs}}$ which were higher at blue wavelengths and lower at green wavelengths. The magnitudes of $b_{b, p}$ were similar between seasons; however, spectral $b_{b, p}$ had a higher inverse wave- 

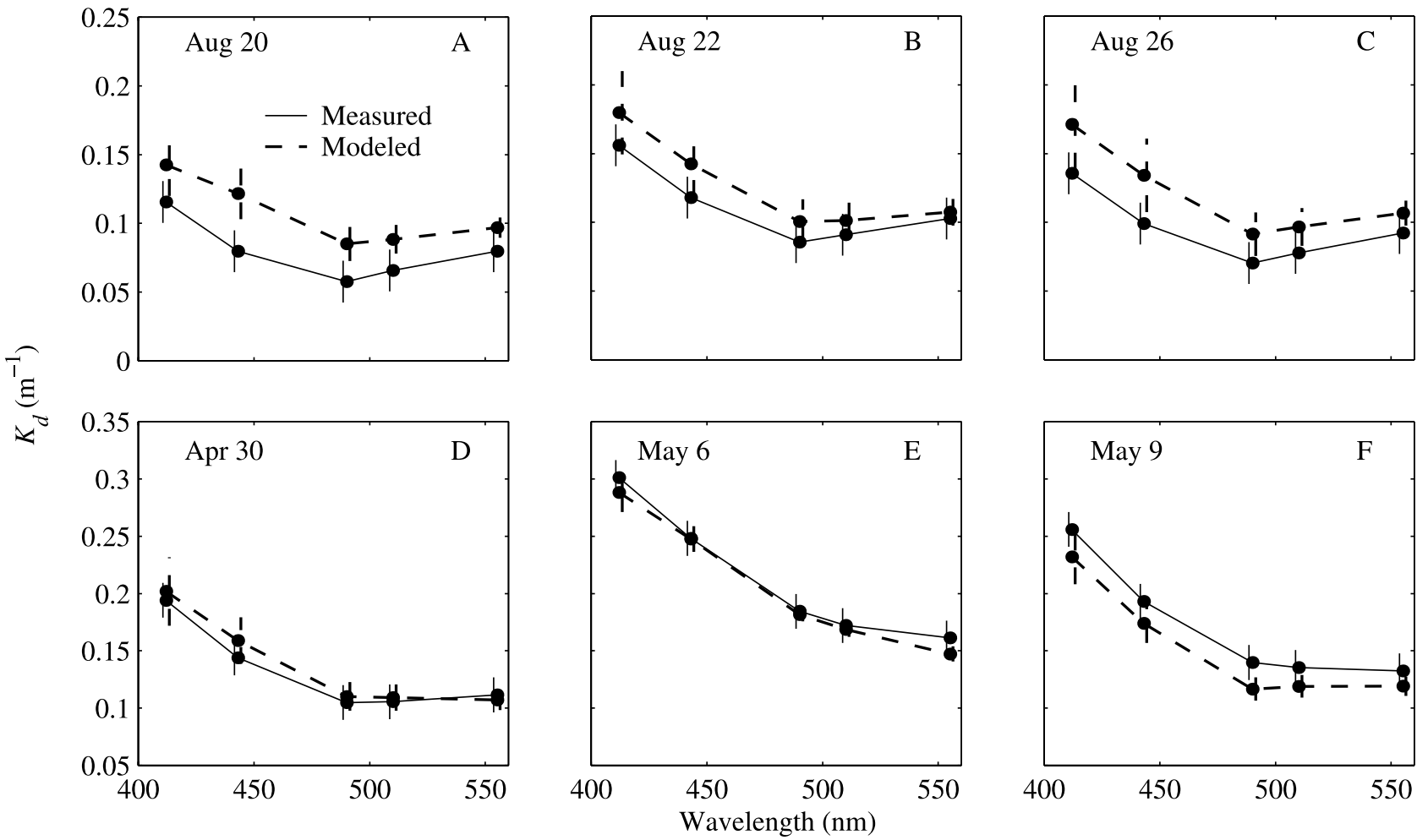

Figure 7. Spectra of measured and modeled $K_{d}$ at $10 \mathrm{~m}$ depth for $(\mathrm{a}-\mathrm{c})$ the summer examples and $(\mathrm{d}-\mathrm{f})$ the spring examples. Standard deviations are plotted for each point as a measure of estimated uncertainties.
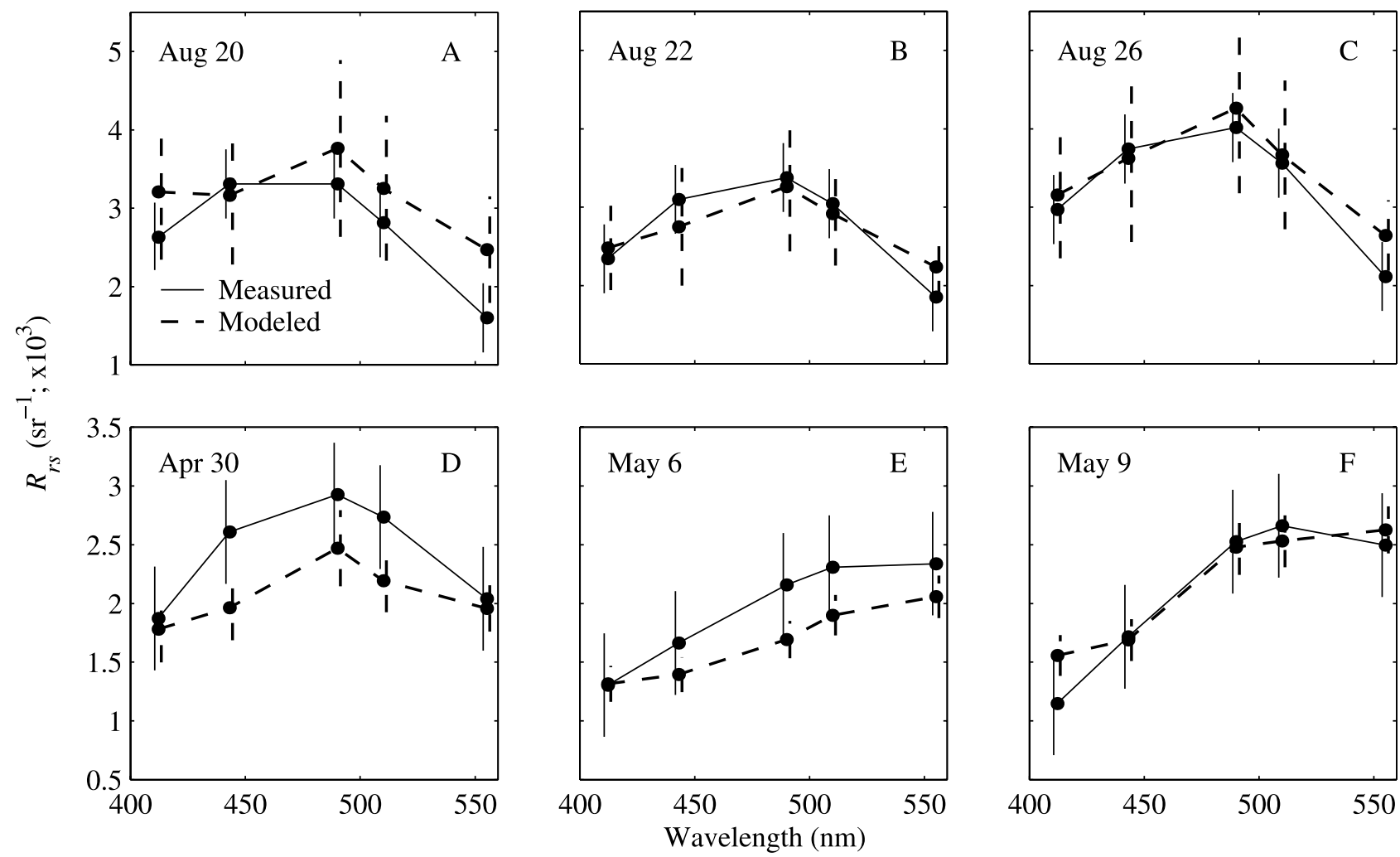

Figure 8. Spectra of measured and modeled $R_{\mathrm{rs}}$ for $(\mathrm{a}-\mathrm{c})$ the summer examples and $(\mathrm{d}-\mathrm{f})$ the spring examples. Standard deviations are plotted for each point as a measure of estimated uncertainties. 

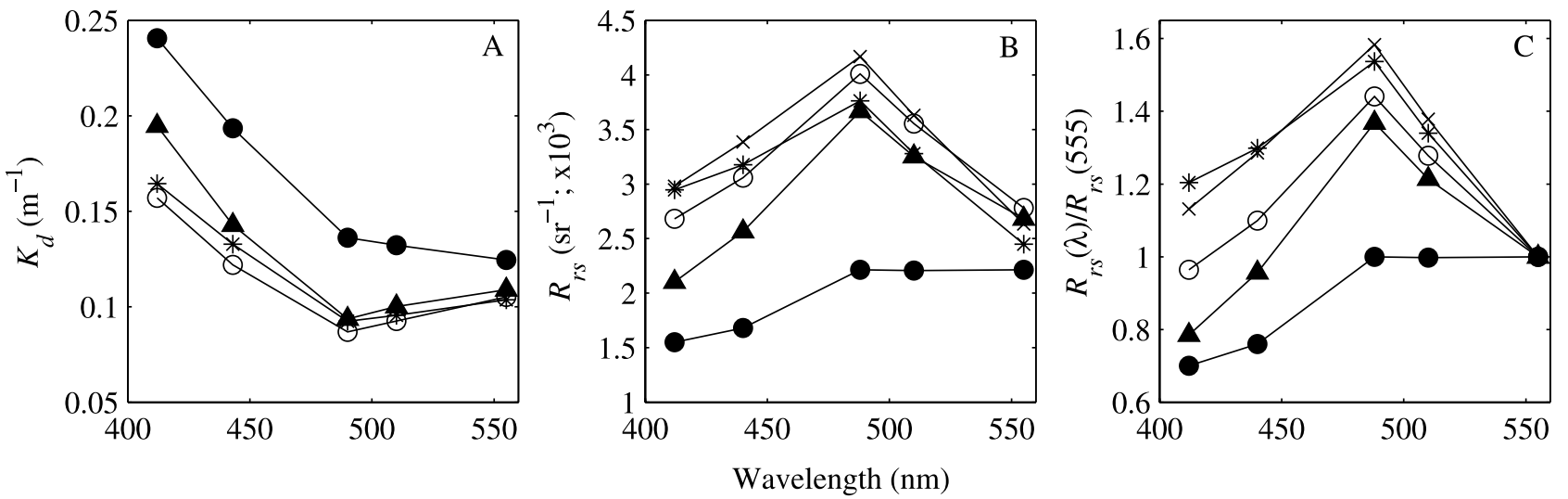

Spring $\quad *$ Summer

Spring $\left(a_{e u k}\right)$

$\bigcirc$ Spring $\left(a_{\text {euk }}, a_{C D O M}\right)$

$\times$ Spring $\left(a_{e u k}, a_{C D O M}, b_{b, d e t}, b_{b, \min }\right)$

Figure 9. Mean spectra of modeled (a) $K_{d}$, (b) $R_{\mathrm{rs}}$, and (c) $R_{\mathrm{rs}}(\lambda) / R_{\mathrm{rs}}(555)$ for the summer and spring examples. In Figure 9a, cases are shown for the actual mean $K_{d}$ spectra for each season and for substitution simulations for the spring examples (noted in parantheses in legend) with spring $a_{\text {euk }}$ replaced by mean summer values, and both spring $a_{\text {euk }}$ and spring $a_{\mathrm{CDOM}}$ replaced by mean summer values. In Figure 9b, cases are shown for the actual mean $R_{\mathrm{rs}}$ spectra for each season and for substitution simulations for the spring examples with spring $a_{\text {euk }}$ replaced by mean summer values, both spring $a_{\text {euk }}$ and $a_{\mathrm{CDOM}}$ replaced by mean summer values, and all of spring $a_{\text {euk }}, a_{\mathrm{CDOM}}, b_{b, \text { det }}$, and $b_{b \text {, min }}$ replaced by mean summer values. In Figure $9 \mathrm{c}, R_{\mathrm{rs}}(\lambda)$ is plotted normalized to $R_{\mathrm{rs}}(555)$ for each scenario.

length dependence in the summer than in the spring (Figure 6a). This result is consistent with the prediction of Sosik et al. [2001] that $b_{b, p}$ had to differ between the two seasons in order to account for the larger difference observed between $R_{\mathrm{rs}}(443) / R_{\mathrm{rs}}(555)$ and $K_{d}(555) / K_{d}(443)$ in the summer than in the spring. Specifically, Sosik et al. predicted that a steeper inverse wavelength dependence and/or higher backscattering efficiency existed for smaller particles in the summer. In concurrence with both predictions, we found a steeper inverse wavelength dependence of $b_{b, p}$ and higher ratios of $b_{b, p} / b_{p}$ in the summer (Figures $6 \mathrm{a}-6 \mathrm{~b}$ ). As discussed above, these were associated with high abundances of small detrital particles and lower $b_{\text {euk }}$.

[29] Spectral variations in $R_{\mathrm{rs}}$ were small within the summer and higher in the spring caused mainly by variability in $a_{\text {euk }}$ and $b_{b, \min }$. The spectral shape of $R_{\mathrm{rs}}$ on April 30 was significantly different than on May 6 and May 9 , with ratios of $R_{\mathrm{rs}}(443) / R_{\mathrm{rs}}(555)$ equal to $1.00,0.68$, and 0.64 , respectively. Values of $a_{\text {total }}$ and $b_{b \text {, min }}$ were the lowest on April 30. The roles of $a_{\text {euk }}$ and $b_{b, \text { min }}$ in determining variability between April 30 and May 6/9 was determined by performing two Hydrolight simulations for April 30: (1) with $a_{\text {euk }}$ replaced by mean May $6 / 9$ values, and (2) with both $a_{\text {euk }}$ and $b_{b, \min }$ replaced by mean May 6/9 values (results not shown). Substitution of $a_{\text {euk }}$ lowered the ratio of $R_{\mathrm{rs}}(443) / R_{\mathrm{rs}}(555)$ from 1.00 to 0.85 , and substitution of both $a_{\text {euk }}$ and $b_{b \text {,min }}$ resulted in a ratio of 0.72 , which is similar to the ratios for May 6/9. Thus changes in both $a_{\text {euk }}$ and $b_{b, \min }$ can explain observed variability in the spectral shape of $R_{\mathrm{rs}}$ during spring.

\subsection{Application of Bio-Optical Models}

[30] Our data set for continental shelf waters provides an opportunity to explore how different constituents affect the performance of current bio-optical models developed for Case 1 waters. These models are generally assumed to apply for open ocean waters but the extent to which they can be used in Case 1 continental shelf waters (e.g., where $a_{\mathrm{CDOM}}$ may be higher or $b_{b}$ more variable) has not been extensively investigated. On the basis of the relationship between $b_{p}$ and [Chl] [Loisel and Morel, 1998], each of our three spring and summer examples were in Case 1 waters. We were interested in evaluating model performance under different seasonal conditions and identifying whether certain constituents cause errors in model retrievals.

[31] The Morel and Maritorena [2001] (MM) model overestimated [Chl] in all examples with a mean difference of $137 \%$ from measured values (Table 2). The model overestimated [Chl], because $R(443) / R(555)$ was overestimated by $52 \%$ and $35 \%$ for the summer and spring, respectively (Figure 10a). Modeled ratios of $R(443) /$ $R(555)$ were higher than measured ratios mainly because the contributions by $a_{\mathrm{CDOM}}$ were underestimated. In the model, $a_{\mathrm{CDOM}}(440)$ is assumed to be a constant fraction (0.2) of $a_{w}(440)+a_{p}(440)$ [Prieur and Sathyendranath, 1981]. In our data, measured values of this fraction were always higher, with mean values equal to $1.29( \pm 0.29)$ in the

Table 2. Comparison of Measured and Modeled [Chl]

\begin{tabular}{lcccc}
\hline & \multicolumn{4}{c}{$[\mathrm{Chl}], \mathrm{mg} \mathrm{m}^{-3}$} \\
\cline { 2 - 5 } \multicolumn{1}{c}{ Date } & Actual & MM & GSM01 & OC4 \\
\hline April 30 & 0.79 & 1.24 & 0.29 & 0.87 \\
May 6 & 2.91 & 6.14 & 1.59 & 3.45 \\
May 9 & 2.20 & 6.98 & 0.63 & 2.18 \\
Aug. 20 & 0.21 & 0.42 & 0.12 & 0.39 \\
Aug. 22 & 0.27 & 0.71 & 0.20 & 0.52 \\
Aug. 26 & 0.21 & 0.57 & 0.21 & 0.45 \\
\hline
\end{tabular}



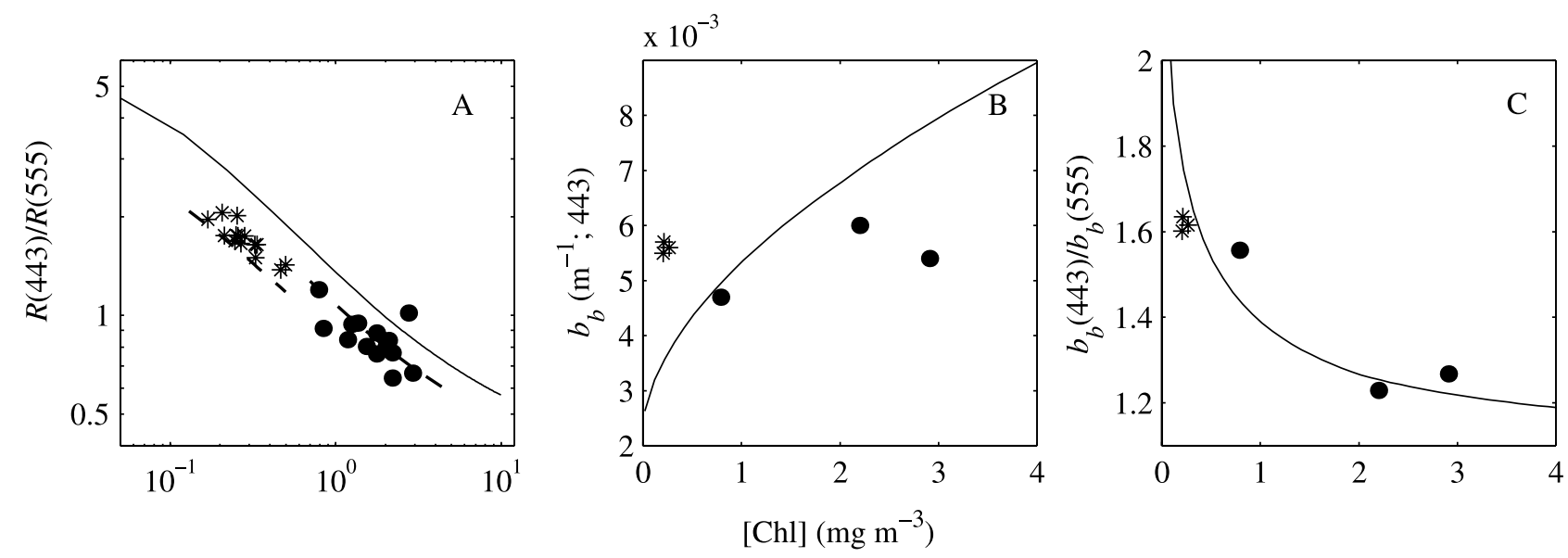

- Spring $\quad$ * Summer $\quad-\mathrm{MM} \quad-\quad \mathrm{MM}, a_{\mathrm{CDOM}}(440)$

Figure 10. Comparison of bio-optically modeled and measured (a) $R(443) / R(555)$, (b) $b_{b}(443)$, and (c), $b_{b}(443) / b_{b}(555)$ at different chlorophyll concentrations at the surface ( $1-5 \mathrm{~m}$ depth). Results are shown both for the MM model, with its assumption of $a_{\mathrm{CDOM}}(440) /\left[a_{w}(440)+a_{p}(440)\right]=0.20$, and for the biooptical model with the measured percentages of $a_{\mathrm{CDOM}}(440)$ in the summer and spring substituted into the model ("MM, $\left.a_{\mathrm{CDOM}}(440) "\right)$. All measured values of $R(443) / R(555)$ are shown in Figure 10a, whereas only the measured values of $b_{b}$ and $b_{b}(443) / b_{b}(555)$ used in the Hydrolight-modeling examples are shown in Figures $10 \mathrm{~b}$ and 10c.

summer and $0.65( \pm 0.25)$ in the spring. When the measured $a_{\mathrm{CDOM}}(440)$ proportions were substituted into the model, the relationships between $[\mathrm{Chl}]$ and $R(440) / R(555)$ were similar for modeled and measured values (Figure 10a); this substitution resulted in [Chl] values determined to within an average of $37 \%$ of measured values. The conclusion that differences in the relationship between $a_{\mathrm{CDOM}}$ and $a_{p}$ can be a source of significant error in this type of reflectance model has also been emphasized in recent reviews [Morel and Maritorena, 2001; Sathyendranath et al., 2001]. In comparison to our findings, similarly large ratios of $a_{\mathrm{CDOM}}$ to $a_{p}$ have been measured throughout midshelf surface waters in the North Atlantic [Nelson and Guarda, 1995; DeGrandpre et al., 1996; Chang et al., 2002], which implies that application of the MM model may need to be modified throughout this oceanic regime.

[32] We also analyzed differences in the magnitude of MM-modeled and measured reflectance. With measured ratios for $a_{\mathrm{CDOM}}(440)$ substituted into the model, the magnitude of $R(440)$ was underestimated in the spring and summer by $42 \%$ and $152 \%$, respectively. The large difference between measured and modeled $R(440)$ in the summer was a direct result of the underestimate of $b_{b}$ for non-phytoplankton in the summer. The model resulted in the underestimation of $b_{b, p}(440)$ by $\sim 59 \%$ in the summer (Figures 10b and 11). However, the spectral shape of $b_{b}$ in both seasons generally agreed with FCM-Mie estimates (Figures 10c and 11). Higher values of $b_{b}$ in the summer compared to model estimates were caused both by higher backscattering efficiencies and higher scattering for nonphytoplankton than were assumed in the model. This was a result of the importance of small detrital particles in the summer. In many cases, bio-optical models for interpreting reflectance consider ratios of $b_{b}$ at two wavelengths, $b_{b}(443) / b_{b}(555)$, thus avoiding errors in absolute magnitude. In fact, ratios of $b_{b}(443) / b_{b}(555)$ in both the summer and spring compared well with modeled values (Figure 10c). The modeled increase in the spectral backscattering ratio with decreasing [Chl], which was also evident in our summer and spring data, is consistent with the idea that particles tend to be relatively smaller in low chlorophyll waters [Sathyendranath et al., 1989; Ulloa et al., 1994].

[33] The Garver-Siegel-Maritorena (GSM01) [Maritorena et al., 2002] model generally underestimated [Chl] (the reverse trend of the MM model) with a mean difference of $41 \%$ from measured values (Table 2). Low values of modeled [Chl] were caused by $a_{\mathrm{ph}}(440)$ that was underestimated by an average of $46 \%$ (Figure 11). Differences between modeled and measured $a_{\mathrm{cdm}}(440)$ were less systematic, with modeled values overestimating measurements by $63 \%$ in spring and underestimating measurements by $9 \%$ in the summer (Figure 11). We could improve GSM01 model-predictions of spring [Chl] by substituting measured values of chlorophyll-specific absorption, $a_{\mathrm{ph}}^{*}(\lambda)$, for the constant values assumed in the model. In comparison to the modeled values of $a_{\mathrm{ph}}^{*}(\lambda)$, measured spring values were significantly higher at 412 and $490 \mathrm{~nm}$, a difference which is also evident if GSM01 $a_{\mathrm{ph}}^{*}(\lambda)$ values are compared to other models [e.g., Morel, 1988; Bricaud et al., 1998]. When we used measured $a_{\mathrm{ph}}^{*}(\lambda)$ values, GSM01 [Chl] retrievals in the spring were within $26 \%$ of measured values. The model generally underestimated $b_{b, p}$ by $28 \%$, considering both seasons (Figure 11). This difference was improved slightly to an underestimate of $20 \%$ when, in addition to using measured $a_{\mathrm{ph}}^{*}$, measured values of $Y$ $(\sim 0.89$ in summer and $\sim-0.21$ in spring versus the 1.03373 assumed in the model) were also substituted into the model. The model was highly sensitive to changes in $S$, 

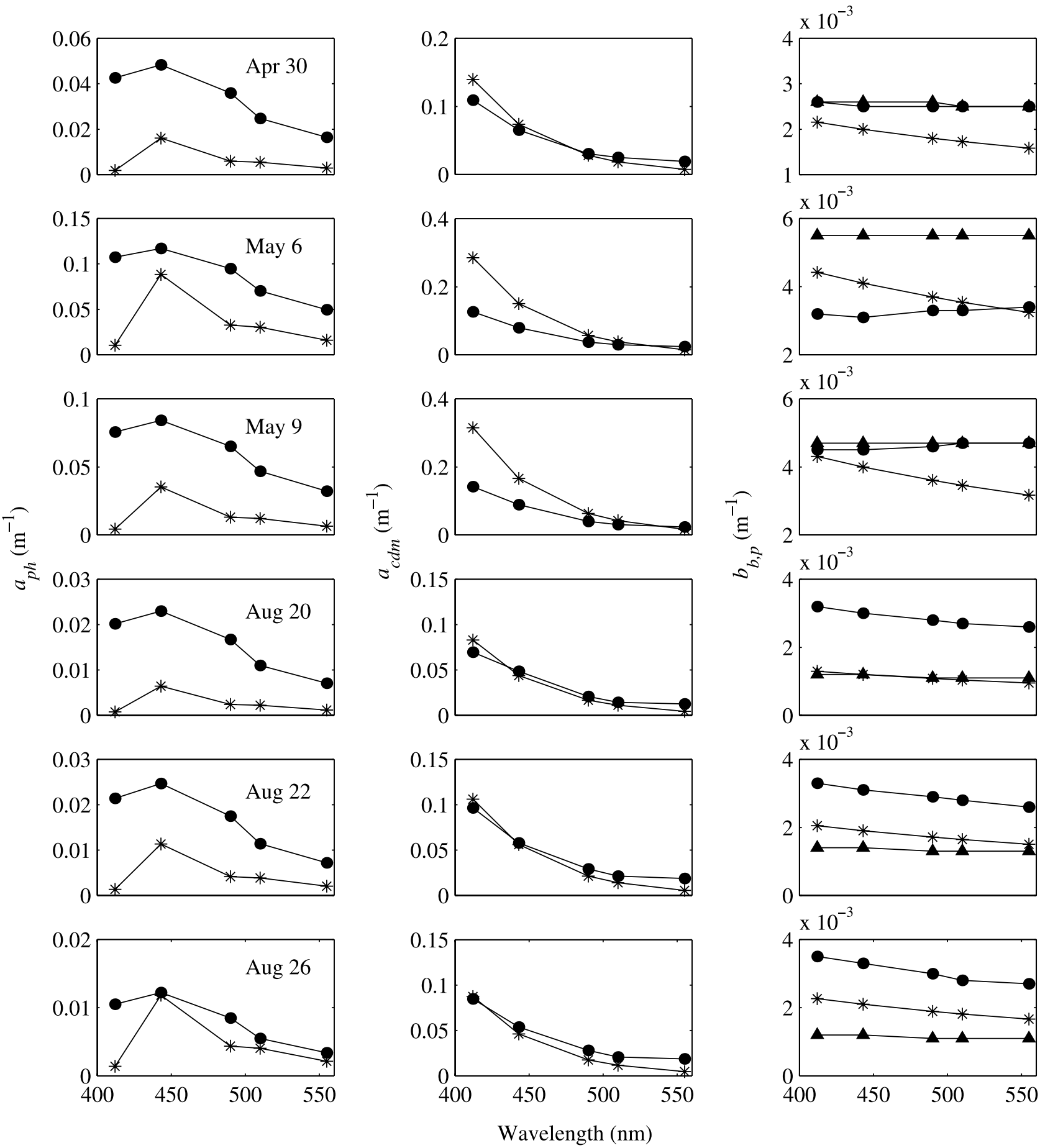

\section{- Measured $\Delta \mathrm{MM} \quad$ * GSM01}

Figure 11. Comparison of bio-optically modeled and measured spectral IOPs, $a_{\mathrm{ph}}$ (column 1), $a_{\mathrm{cdm}}$ (column 2), and $b_{b, p}$ (column 3), for each summer and spring example. Each row corresponds to the day noted in the first column. MM model results are not included in the $a_{\mathrm{ph}}$ and $a_{\mathrm{cdm}}$ plots, because $a_{p}$ and $a_{\mathrm{CDOM}}$ are obtained from the model.

however, changing $S$ to measured values $(0.015$ versus the 0.02061 assumed in the model) decreased the accuracy of [Chl] retrievals in both seasons.

[34] The GSM01 model performed better than the MM model in retrieving [Chl]. The better performance of this model can be attributed to its being more computationally rigorous since a spectral optimization approach was used to determine the model parameters. This improvement in performance is paid for in increased computational time, which may be a factor in the processing of many data points 
(e.g., the processing of ocean color imagery). For comparison, the current chlorophyll algorithm used for global processing of SeaWiFS data (the SeaBAM OC4 model), which is purely empirical, determined [Chl] accurately in the spring (within 10\%) and less accurately in the summer (within 99\%) for a mean difference of 54\% from measured values, considering both seasons (Table 2). The GSM01 model performed slightly better than this algorithm in [Chl] retrievals. On the basis of our data, we suggest that application of two-band models (such as the MM model) to New England continental shelf waters could be improved by (1) increasing $a_{\mathrm{CDOM}}$ relative to $a_{w}+a_{p}$, and (2) increasing $b_{b, p}$ in the summer (to account for small detrital particles). In contrast, application of the spectral optimization model, GSM01, could be improved by: (1) increasing the contribution of $a_{\mathrm{ph}}(440)$ by changing $a_{\mathrm{ph}}^{*}$, and (2) implementing a scheme such as that used in the MM model, whereby $Y$ is lower at high [Chl] (as in spring) and higher at low [Chl] (as in summer). Our analysis is certainly not an exhaustive study of current bio-optical models. We have only presented two examples of semianalytical models and there are several other models deserving of similar attention [e.g., Roesler and Perry, 1995; Reynolds et al., 2001; Lee et al., 2002].

\section{Conclusions}

[35] We have shown that eukaryotic phytoplankton absorption and CDOM absorption, as well as mineral backscattering and detrital backscattering (though certainly based on less direct evidence), were the most important contributors to variability in AOPs both within and between seasons at our study site in New England continental shelf waters. Surface water values of $K_{d}, a_{\text {euk }}$, and $a_{\mathrm{CDOM}}$ were higher in the spring when the water column was less stratified than in the summer. This was most likely a result of higher nutrients in spring surface waters available for phytoplankton growth and a shorter period of stratification which minimized losses of $a_{\mathrm{CDOM}}$ due to photooxidation. In addition to differences in absorption, values of $R_{\mathrm{rs}}$ were affected by differences in the spectral shape of $b_{b \text {,total }}$, which was strongly influenced by the high abundance of submicron detritus in the summer and the abundance of minerals of all sizes in both seasons.

[36] Our results for the contribution of non-phytoplankton to $b_{b}$ depend on the extrapolation of submicron size distributions for detritus and minerals, assumptions regarding their optical properties, and the uncertainties associated with the use of Mie-scattering calculations for homogenous spheres. There is no consensus in the literature that nonliving particles dominate $b_{b}$, but there is consensus that based on Mie theory they are likely to dominate [Stramski and Kiefer, 1991; Stramski et al., 2001; Green et al., 2003b]. In fact, recent studies suggest that phytoplankton may have higher $b_{b}$ than calculated from Mie theory [Piskozub and Stramski, 2000; Vaillancourt et al., 2000]. Given that submicron non-phytoplankton particles were not directly measured in the present study, we cannot be certain of their contributions to $b_{b}$, but our findings are consistent with the idea that $b_{b}$ was dominated by the non-phytoplankton fraction. Future assessments of detrital and mineral backscattering would benefit from concurrent measure- ments of bulk $b_{b}$ [Maffione and Dana, 1997], improved methods for optical characterization of submicron nonphytoplankton particles, and spectral application of Mie theory incorporating the distributions of $n$ for particles, especially for minerals which have a broader range of $n$ and $n^{\prime}$ than do organic particles. Despite these needs for future research, our present results support the idea that seasonal differences in the spectral shape of $R_{\mathrm{rs}}$ in New England coastal waters are affected by differences in the size distributions, abundance, and type of non-phytoplankton particles. An important example of this was the effect of a higher abundance of submicron detrital particles in late summer surface waters.

[37] The type of modeling we present using Hydrolight and constituent IOPs provides a powerful means for separating and understanding the effects of different seawater constituents on oceanic light fields, of particular importance to bio-optical (or ocean color) algorithms. There are a variety of bio-optical models for estimating [Chl] and IOPs from reflectance, and we explored how two of these perform in New England continental shelf waters. These models rely on a variety of assumptions, including relationships between IOPs and [Chl] and/or predetermined spectral shapes for $a_{\mathrm{CDOM}}, a_{\mathrm{ph}}$, and $b_{b, p}$. In application to our study site, we have proposed changes to these assumptions for the improved estimation of [Chl] and IOPs. With regards to $b_{b, p}$, about which little is presently known, it appears that seasonal differences in the contributions of detrital particles in New England continental shelf waters needs to be accounted for in bio-optical models. Despite apparent Case 1 conditions during much of our sampling, our results emphasize that the performance of globally parameterized models can be limited by differences in CDOM absorption, chlorophyll a specific phytoplankton absorption, and/or particulate backscattering between these coastal waters and typical open ocean waters.

[38] Acknowledgments. We thank S. Pegau and R. Zaneveld for ac-9 data, C. Roesler for discrete spectrophotometric and chlorophyll analysis, and R. Olson, A. Shalapyonok, and M. DuRand for assistance in the laboratory. We also thank S. Maritorena for help with implementation of the GSM01 model. R. Olson, S. Chisholm, C. Mobley, and A. Solow provided critical comments on an early draft of the manuscript. E. Boss and an anonymous reviewer provided constructive comments that improved this work. Financial support was provided by ONR grants N00014-95-1-0333 and N00014-96-1-0965 (H. Sosik and R. Olson), NASA grants NAGW517, NAG5-7538, and NAG5-8868, and a NASA Earth System Science Fellowship (R. Green). This is WHOI contribution 10915.

\section{References}

Aas, E. (1996), Refractive index of phytoplankton derived from its metabolite composition, J. Plankton Res., 18, 2223-2249.

Ahn, Y. H., A. Bricaud, and A. Morel (1992), Light backscattering efficiency and related properties of some phytoplankters, Deep Sea Res., 39, $1835-1855$

Balch, W. M., D. T. Drapeau, J. J. Fritz, B. C. Bowler, and J. Nolan (2001), Optical backscattering in the Arabian Sea-Continuous underway measurements of particulate inorganic and organic carbon, Deep Sea Res., Part I, 48, 2423-2452.

Boss, E., W. S. Pegau, J. R. V. Zaneveld, and A. H. Barnard (2001), Spatial and temporal variability of absorption by dissolved material at a continental shelf, J. Geophys. Res., 106(C5), 9499-9507.

Bricaud, A., A. Morel, M. Babin, K. Allali, and H. Claustre (1998), Variations of light absorption by suspended particles with chlorophyll $a$ concentration in oceanic (case 1) waters: Analysis and implications for bio-optical models, J. Geophys. Res., 103(C13), 31,033-31,044.

Brown, O. B., and H. R. Gordon (1973), Two component Mie scattering models of Sargasso Sea particles, Appl. Opt., 12, 2461-2465. 
Chang, G. C., T. D. Dickey, O. M. Schofield, A. D. Weidemann, E. Boss, W. S. Pegau, M. A. Moline, and S. M. Glenn (2002), Nearshore physical processes and bio-optical properties in the New York Bight, J. Geophys. Res., 107(C9), 3133, doi:10.1029/2001JC001018.

Clark, D. K. (1981), Phytoplankton algorithms for the Nimbus 7 CZCS, in Oceanography from Space, edited by J. R. F. Gower, pp. 227-238, Plenum, New York.

DeGrandpre, M. D., A. Vodaceck, R. K. Nelson, E. J. Bruce, and N. V. Blough (1996), Seasonal seawater optical properties of the U.S. Middle Atlantic Bight, J. Geophys. Res., 101(C10), 22,727-22,736.

Fournier, G. R., and J. L. Forand (1994), Analytic phase function for ocean water, Ocean Optics XII, Proc. SPIE Int. Soc. Opt. Eng., 2258, 194-201.

Fournier, G. R., and M. Jonasz (1999), Computer-based underwater imaging analysis, in Airborne and In-Water Underwater Imaging, edited by G. D. Gilbert, Proc. SPIE Int. Soc. Opt. Eng., 3761, 62-70.

Garver, S., and D. Siegel (1997), Inherent optical property inversion of ocean color spectra and its biogeochemical interpretation: 1. Time Series from the Sargasso Sea, J. Geophys. Res., 102(C8), 18,607-18,625.

Gordon, H. R., and A. Morel (1983), Remote Assessment of Ocean Color for Interpretation of Satellite Visible Imagery, a Review, Lecture Notes on Coastal and Estuarine Stud., vol. 4, 113 pp., Springer-Verlag, New York.

Gordon, H. R., O. B. Brown, and M. M. Jacobs (1975), Computed relationships between the inherent and apparent optical properties of a flat homogeneous ocean, Appl. Opt., 14, 417-427.

Gordon, H. R., O. B. Brown, R. H. Evans, J. W. Brown, R. C. Smith, K. S. Baker, and D. K. Clark (1988), A semianalytic radiance model of ocean color, J. Geophys. Res., 93(D9), 10,909-10,924.

Green, R. E., H. M. Sosik, R. J. Olson, and M. D. DuRand (2003a), Flow cytometric determination of size and complex refractive index for marine particles: Comparison with bulk measurements, Appl. Opt., $42,526-541$

Green, R. E., H. M. Sosik, and R. J. Olson (2003b), Contributions of phytoplankton and other particles to inherent optical properties in New England continental shelf waters, Limnol. Oceanogr., 48, 2377-2391.

Gregg, W. W., and K. L. Carder (1990), A simple spectral solar irradiance model for cloudless maritime atmospheres, Limnol. Oceanogr., 35, $1657-1675$

Harrison, A. W., and C. A. Coombes (1988), An opaque cloud cover model of sky short wavelength radiance, Sol. Energy, 41, 387-392.

Hawes, S. K. (1992), Quantum fluorescence efficiencies of marine fulvic and humic acids, M.S. thesis, Dep. of Mar. Sci., Univ. of S. Fla., St. Petersburg, Fla.

Kishino, M., N. Takahashi, N. Okami, and S. Ichimura (1985), Estimation of the spectral absorption coefficients of phytoplankton in the sea, Bull. Mar. Sci., 37, 634-642.

Koike, I., S. Hara, K. Terauchi, and K. Kogure (1990), Role of sub-micrometre particles in the ocean, Nature, 345, 242-244.

Lee, Z. P., K. L. Carder, and R. A. Arnone (2002), Deriving inherent optical properties from water color: A multiband quasi-analytical algorithm for optically deep waters, Appl. Opt., 41, 5755-5772.

Loisel, H., and A. Morel (1998), Light scattering and chlorophyll concentration in case 1 waters: A reexamination, Limnol. Oceanogr., 43, 847858 .

Macdonald, J. B., M. S. Twardowski, W. S. Pegau, A. H. Barnard, E. Boss, and J. R. V. Zaneveld (2000), Characterization of spectral backscattering in the Gulf of California, Eos Trans. $A G U, 80$, Ocean Sci. Meet. Suppl., OS22E-12.

Maffione, R. A., and D. R. Dana (1997), Instruments and methods for measuring the backward-scattering coefficient of ocean waters, Appl. Opt., 36, 6057-6067.

Maritorena, S., D. A. Siegel, and A. R. Peterson (2002), Optimization of a semianalytical ocean color model for global-scale applications, Appl. Opt., 41, 2705-2714.

Mobley, C. D. (1994), Light and Water: Radiative Transfer in Natural Waters, 592 pp., Academic, San Diego, Calif.

Mobley, C. D., and D. Stramski (1997), Effects of microbial particles on oceanic optics: Methodology for radiative transfer modeling and example simulations, Limnol. Oceanogr., 42, 550-560.

Mobley, C. D., L. K. Sundman, and E. Boss (2002), Phase function effects on oceanic light fields, Appl. Opt., 41, 1035-1050.

Morel, A. (1974), Optical properties of pure water and pure sea water, in Optical Aspects of Oceanography, edited by N. G. Jerlov and E. S. Nielsen, pp. 1-24, Academic, San Diego, Calif.

Morel, A. (1988), Optical modeling of the upper ocean in relation to its biogenous matter content (case 1 waters), J. Geophys. Res., 93(C9), $10,749-10,768$

Morel, A., and B. Gentili (1993), Diffuse reflectance of oceanic waters: II. Bi-directional aspects, Appl. Opt., 32, 6864-6879.

Morel, A., and S. Maritorena (2001), Bio-optical properties of oceanic waters: A reappraisal, J. Geophys. Res., 106(C4), 7163-7180.
Morel, A., and L. Prieur (1977), Analysis of variations in ocean color, Limnol. Oceanogr., 22, 709-722.

Mueller, J. L., and R. W. Austin (1995), Ocean optics protocols for SeaWiFS validation, revision 1, NASA Tech. Memo., 104566, 67 pp.

Nagata, T., and D. L. Kirchman (1996), Roles of submicron particles and colloids in microbial food webs and biogeochemical cycles within marine environments, Adv. Microb. Ecol., 15, 81-103.

Nelson, J. R., and S. Guarda (1995), Particulate and dissolved spectral absorption on the continental shelf of the southeastern United States, J. Geophys. Res., 100(C5), 8715-8732.

O’Reilly, J. E., S. Maritorena, B. G. Mitchell, D. A. Siegel, K. L. Carder, S. A. Garver, M. Kahru, and C. R. McClain (1998), Ocean color chlorophyll algorithms for SeaWiFS, J. Geophys. Res., 103(C11), 24,937-24,953.

Pegau, W. S., et al. (1995), A comparison of methods for the measurement of the absorption coefficient in natural waters, J. Geophys. Res., 100(C7), $13,201-13,220$.

Piskozub, J., and D. Stramski (2000), The use of scattering error in absorption measurement for estimating the scattering phase function for marine phytoplankton, paper presented at Ocean Optics XV, SPIE Int. Soc. of Opt. Eng., Bellingham, Wash.

Pope, R. M., and E. S. Fry (1997), Absorption spectrum (380-700 nm) of pure water: II. Integrating cavity measurements, Appl. Opt., 36, 87108723.

Prieur, L., and S. Sathyendranath (1981), An optical classification of coastal and oceanic waters based on the specific spectral absorption curves of phytoplankton pigments, dissolved organic matter, and other particulate materials, Limnol. Oceanogr., 26, 671-689.

Reynolds, R. A., D. Stramski, and B. G. Mitchell (2001), A chlorophylldependent semianalytical reflectance model derived from field measurements of absorption and backscattering coefficients within the Southern Ocean, J. Geophys. Res., 106(C4), 7125-7138.

Roesler, C. S., and M. J. Perry (1995), In situ phytoplankton absorption, fluorescence emission, and particulate backscattering spectra determined from reflectance, J. Geophys. Res., 100(C7), 13,279-13,294

Roesler, C. S., M. J. Perry, and K. L. Carder (1989), Modeling in situ phytoplankton absorption from total absorption spectra in productive inland marine waters, Limnol. Oceanogr., 34, 1510-1523.

Sathyendranath, S., L. Lazzara, and L. Prieur (1987), Variations in the spectral values of specific absorption of phytoplankton, Limnol. Oceanogr., 32, 403-415.

Sathyendranath, S., L. Prieur, and A. Morel (1989), A three-component model of ocean colour and its application to remote sensing of phytoplankton pigments in coastal waters, Int. J. Remote Sens., 10, $1373-$ 1394.

Sathyendranath, S., G. Cota, V. Stuart, H. Maass, and T. Platt (2001), Remote sensing of phytoplankton pigments: A comparison of empirical and theoretical approaches, Int. J. Remote Sens., 22, 249-273.

Shibata, A., K. Kogure, I. Koike, and K. Ohwada (1997), Formation of submicron colloidal particles from marine bacteria by viral infection, Mar. Ecol. Prog. Ser., 155, 303-307.

Sieracki, M., and C. Viles (1992), Distributions and fluorochrome-staining properties of sub-micrometer particles and bacteria in the North Atlantic, Deep Sea Res., 39, 1919-1929.

Smith, R. C., and K. S. Baker (1984), The analysis of ocean optical data, Ocean Optics VII, Proc. SPIE Int. Soc. Opt. Eng., 489, 119-126.

Smith, R. C., and K. S. Baker (1986), Analysis of ocean optical data II, Ocean Optics VIII, Proc. SPIE Int. Soc. Opt. Eng., 637, 95-107.

Sosik, H. M., R. E. Green, W. S. Pegau, and C. S. Roesler (2001), Temporal and vertical variability in optical properties of New England shelf waters during late summer and spring, J. Geophys. Res., 106(C5), 9455-9472.

Stramska, M., D. Stramski, R. Hapter, S. Kaczmarek, and J. Stoń (2003), Bio-optical relationships and ocean color algorithms for the north polar region of the Atlantic, J. Geophys. Res., 108(C5), 3143, doi:10.1029/ 2001JC001195.

Stramski, D., and D. A. Kiefer (1991), Light scattering by microorganisms in the open ocean, Prog. Oceanogr., 28, 343-383.

Stramski, D., and C. D. Mobley (1997), Effects of microbial particles on oceanic optics: A database of single-particle optical properties, Limnol. Oceanogr., 42, 538-549.

Stramski, D., R. A. Reynolds, M. Kahru, and B. G. Mitchell (1999), Estimation of particulate organic carbon in the ocean from satellite remote sensing, Science, 285, 239-242.

Stramski, D., A. Bricaud, and A. Morel (2001), Modeling the inherent optical properties of the ocean based on the detailed composition of the planktonic community, Appl. Opt., 40, 2929-2945.

Terrill, E. J., W. K. Melville, and D. Stramski (2001), Bubble entrainment by breaking waves and their influence on optical scattering in the upper ocean, J. Geophys. Res., 106(C8), 16,815-16,823.

Twardowski, M. S., E. Boss, J. B. Macdonald, W. S. Pegau, A. H. Barnard, and J. R. V. Zaneveld (2001), A model for estimating bulk refractive 
index from the optical backscattering ratio and the implications for understanding particle composition in case I and case II waters, J. Geophys. Res., 106(C7), 14,129-14,142.

Ulloa, O., S. Sathyendranath, and T. Platt (1994), Effect of the particle-size distribution on the backscattering ratio in seawater, Appl. Opt., 33, 70707077.

Vaillancourt, R. D., C. Brown, and R. R. L. Guillard (2000), A taxonomic survey of the optical properties of marine phytoplankton with special emphasis on the backscattering coefficient, Eos Trans. $A G U, 80,119-120$.

Vodacek, A., N. V. Blough, M. D. DeGranpre, E. T. Peltzer, and R. K.

Nelson (1997), Seasonal variations of CDOM and DOC in the Middle Atlantic Bight: Terrestrial inputs and photooxidation, Limnol. Oceanogr., 42, 674-686.

Yamasaki, A., H. Fukuda, R. Fukuda, T. Miyajima, T. Nagata, H. Ogawa, and I. Koike (1998), Submicrometer particles in northwest Pacific coastal environments: Abundance, size distribution, and biological origins, Limnol. Oceanogr., 43, 536-542.

Zaneveld, J. R. V., D. M. Roach, and H. Pak (1974), The determination of the index of refraction distribution of oceanic particulates, J. Geophys. Res., 79(27), 4091-4095.

Zhang, X., M. Lewis, M. Lee, B. Johnson, and G. Korotaev (2002), The volume scattering function of natural bubble populations, Limnol. Oceanogr., 47, 1273-1282.

R. E. Green and H. M. Sosik, Biology Department, Woods Hole Oceanographic Institution, Woods Hole, MA 02543, USA. (hsosik@ whoi.edu) 